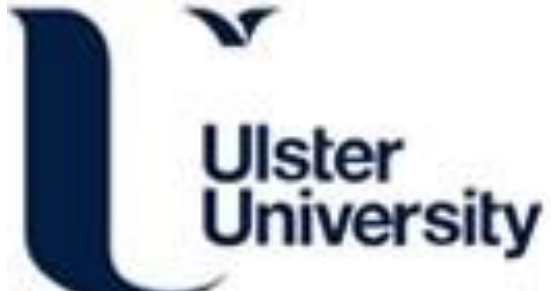

\section{Anticipated Task Difficulty Provokes Pace Conservation and Slower Running Performance}

Brick, N., Fitzpatrick, B., Turkington, R., \& Mallett, J. (2019). Anticipated Task Difficulty Provokes Pace Conservation and Slower Running Performance. Medicine \& Science in Sports \& Exercise, 51(4), 734-743. https://doi.org/10.1249/MSS.0000000000001844

Link to publication record in Ulster University Research Portal

\section{Published in:}

Medicine \& Science in Sports \& Exercise

Publication Status:

Published (in print/issue): 01/04/2019

DOI:

10.1249/MSS.0000000000001844

\section{Document Version}

Author Accepted version

\section{General rights}

Copyright for the publications made accessible via Ulster University's Research Portal is retained by the author(s) and / or other copyright owners and it is a condition of accessing these publications that users recognise and abide by the legal requirements associated with these rights.

\section{Take down policy}

The Research Portal is Ulster University's institutional repository that provides access to Ulster's research outputs. Every effort has been made to ensure that content in the Research Portal does not infringe any person's rights, or applicable UK laws. If you discover content in the Research Portal that you believe breaches copyright or violates any law, please contact pure-support@ulster.ac.uk. 


\section{Medicine \& Science \\ IN \\ Sports \& Exercise}

The Official Journal of the American College of Sports Medicine www.acsm-msse.org

... Published ahead of Print

\section{Anticipated Task Difficulty Provokes Pace Conservation and Slower Running Performance}

Noel E. Brick ${ }^{1}$, Ben L. Fitzpatrick ${ }^{2}$, Robin Turkington ${ }^{2}$, and John C. Mallett ${ }^{1}$

${ }^{1}$ School of Psychology, Ulster University, Northern Ireland, United Kingdom

${ }^{2}$ School of Sport, Ulster University, Northern Ireland, United Kingdom

Accepted for Publication: 31 October 2018

Medicine \& Science in Sports \& Exercise ${ }_{\circledast}$ Published ahead of Print contains articles in unedited manuscript form that have been peer reviewed and accepted for publication. This manuscript will undergo copyediting, page composition, and review of the resulting proof before it is published in its final form. Please note that during the production process errors may be discovered that could affect the content. 


\title{
Anticipated Task Difficulty Provokes Pace Conservation and Slower Running Performance
}

\author{
Noel E. Brick ${ }^{1}$, Ben L. Fitzpatrick ${ }^{2}$, Robin Turkington ${ }^{2}$, and John C. Mallett ${ }^{1}$ \\ ${ }^{1}$ School of Psychology, Ulster University, Northern Ireland, United Kingdom \\ ${ }^{2}$ School of Sport, Ulster University, Northern Ireland, United Kingdom
}

Corresponding author details: Dr Noel E. Brick. School of Psychology, Ulster University, Cromore Road, Coleraine, Northern Ireland, UK. BT52 1SA.

Telephone: $+44(0) 2871675366$.

Email: n.brick@ulster.ac.uk

ORCHID: 0000-0002-3714-4660

This study received no sources of funding. The authors have no conflicts of interest to report. The results do not constitute endorsement by the ACSM and are presented clearly, honestly, and without fabrication, falsification, or inappropriate data manipulation. 


\begin{abstract}
Purpose: Models of self-paced endurance performance suggest that accurate knowledge of the exercise end-point influences pace-related decision-making. No studies have examined the effects of anticipated task difficulty during equidistant endurance activities. Accordingly, the purpose of this study was to investigate the effects of anticipated task difficulty on pacing, psychological, and physiological responses during running time-trials. Methods: Twenty-eight trained runners completed three self-paced $3000 \mathrm{~m}$ time-trials. The first was a baseline (BL) time-trial completed on a $0 \%$ treadmill gradient. Time-trials 2 and 3 were counterbalanced. Before a known incline (KI) time-trial, anticipated to be more difficult, subjects were accurately informed that the gradient would increase to $7 \%$ for the final $800 \mathrm{~m}$. Before an equivalent, unknown incline (UI) time-trial subjects were deceptively informed that the gradient would remain at $0 \%$ throughout. Results: Expressed relative to BL, running speed was $2.44 \%$ slower $(d$ $=-0.47$ ) over the first $2200 \mathrm{~m}$ during KI than UI. Effort perception, affective valence, heart rate, and blood lactate did not differ between time-trials. Initial running speed during KI was related to pre-trial motivation, pre-trial vigor, perceived effort, and affective valence (all $r \geq .382$ ). No such relationships existed during UI. More subjects also reported a conscious focus on pacing during KI. Conclusion: An anticipated increase in task difficulty provoked pace conservation during $3000 \mathrm{~m}$ running time-trials. The reduced pace may have resulted from greater task uncertainty and consciously aware, effort- and affect-based decisions to conserve energy and maintain hedonic state during KI. The findings add to theoretical understandings of factors that influence pacing during endurance activity. Consequently, recommendations to minimize the potentially deleterious effects of anticipated increases in task difficulty are provided.
\end{abstract}

Keywords: Pacing; decision-making; endurance performance; perceived effort; affective valence; attentional focus 


\section{Introduction}

Pacing during endurance activity has been described as a decision-making process involving how and when athletes invest their energy (1). As such, the pacing strategy and tactics adopted often depend on an individual's personal goals and motivation and the likely demands of the activity (1-5). Research on pace-related decision-making has burgeoned in recent years with a plethora of review and perspective articles dedicated to the topic (1-8). The field is not without contention, however, and rich debate surrounds the mechanisms underpinning endurance performance. Foremost amongst these is whether the brain controls muscular activity by conscious $(4,9)$, subconscious $(5,10)$, or alternative processes such as regulation at different levels of awareness (2) or via the dual processes of intuitive and deliberative action (6).

Despite fundamental conceptual differences, most contemporary viewpoints agree on some psychological and contextual factors that determine endurance performance. Of these, perceived effort, the conscious sensation of how hard a task feels (11), and previous experience of endurance tasks of varying distances and duration are considered crucial to effective pacerelated decision-making $(4,9,10,12)$. Others have suggested that affective state may also play a primary or mediatory role in pace-regulation $(7,13)$. Central to the present study, there is also broad consensus that accurate knowledge of the distance/duration of a task is an important contextual factor influencing pace-related decision-making $(1,4,5,9,10,14)$. As such, studies manipulating knowledge of the exercise end-point have demonstrated an impact on perceptual, attentional, and physiological responses during endurance performance. An early investigation involving two $20 \mathrm{~min}$ runs at $85 \%$ of $\dot{\mathrm{VO}}_{2} \max (15)$, for example, found subjects reported a lower perception of effort when completing a trial they believed would last for 30 min in comparison with a known duration trial of 20 min. Later, Baden et al. (16) noted reduced effort perceptions when subjects expected to run for $20 \mathrm{~min}$ in comparison with a known 10 min trial. Attentional focus also tended toward greater associative thoughts (e.g. focusing on bodily sensations, movement technique, relaxing (17)) that correlated with effort perceptions in the known 10 min trial. Finally, Baden and colleagues (18) demonstrated how an unexpected increase in exercise duration altered responses during fixed-intensity 20 min running trials such that effort perceptions and oxygen consumption increased significantly more at the end of an expected $10 \mathrm{~min}$ run when the duration was unexpectedly extended for an additional $10 \mathrm{~min}$. The 
authors suggested that the outcomes were influenced by increased negative affect and associative thoughts when expectations of the exercise duration were not met.

In contrast to knowledge of task distance/duration, little is known about the impact of anticipated task difficulty on regulatory processes during equidistant endurance tasks. The objective difficulty of an endurance activity is often judged according to the route profile (19). Major marathons, for example, are completed over relatively flat courses (e.g. Chicago, Berlin) or courses with notable changes in elevation, such as the 3.3\% 'Heartbreak Hill' incline in the latter stages of the Boston marathon (20). Similarly, cycling events take place on flat, hilly, or mountainous routes and other environmental factors such as terrain (21) or wind speed (22) also impact on task difficulty and, consequently, endurance performance. Accordingly, how anticipated task difficulty influences pacing, psychological, and physiological responses in advance of increases in actual task difficulty is of primary interest in this study.

Research manipulating anticipated exercise duration also highlights the relationship between individuals' associative focus of attention and perceptual responses during task performance $(15,16,18)$. None of these studies identified the specific cognitions engaged by study subjects, however. This may be important as traditionally associative thoughts have contrasting effects on perceptual and performance outcomes during endurance activity. Recently, Brick and colleagues $(17,23)$ recategorized associative thoughts as either active self-regulation (e.g. focus on relaxing, optimizing technique, use of motivational self-talk), internal sensory monitoring (e.g. breathing, effort sensations), or outward monitoring (e.g. route profile, distance indicators). Importantly, active self-regulatory thoughts were typically found to enhance endurance performance without necessarily elevating perceptions of effort (17). In contrast, an excessive focus on internal sensory monitoring may increase effort perceptions and/or reduce pace during self-paced endurance tasks (17,23,24). As such, insight into individuals' specific thoughts may provide a more nuanced understanding of the effects of prior knowledge of contextual factors on endurance performance outcomes.

Accordingly, the purpose of this study was to investigate the effects of anticipated task difficulty on pacing, psychological, and physiological responses during $3000 \mathrm{~m}$ time-trials. We also sought to determine subjects' thought content using Brick and colleagues' (17) attentional focus categorization. The main outcome of interest was pacing and it was hypothesized that 
initial running speed would be slower when subjects anticipated an increase in task difficulty later in a time-trial. Given its importance to pace-regulation, we also hypothesized an elevated perception of effort during the initial stages of time-trials expected to increase in difficulty.

\section{Methods}

Subjects, ethics, and informed consent

Baden and colleagues $(16,18)$ reported moderate-to-large differences in psychological outcomes when manipulating anticipated task duration during fixed-intensity trials. Thus, an a priori analysis (G*Power version 3.1.9.2; Repeated Measures (RM) ANOVA, within factors) with a moderate effect size $(f=0.25)$, a power of 0.80 , an alpha-level of 0.05 , for three conditions, a modest correlation among repeated measures $(r=0.50)$, and a nonsphericity correction $(\varepsilon=1)$ suggested a sample size of 28 . Accordingly, 28 trained endurance runners (Table 1) of performance levels 2 (i.e. several years' running experience, training approximately $2 \mathrm{~h} \cdot \mathrm{d}^{-1}$ at least $3 \mathrm{~d} \cdot \mathrm{wk}^{-1}$ ) to 3 (i.e. up to 10 years' experience, training frequently at least $5 \mathrm{~h} \cdot \mathrm{wk}^{-1}$ ) (25) were recruited. Volunteer subjects were given no incentives to participate and were healthy, injury free, and accustomed to treadmill running. The study was approved by the Ulster University School of Psychology research ethics committee and written informed consent was obtained from all subjects before participation.

Study design and procedures

Subjects visited the laboratory on four occasions, each 3-7 days apart and at the same time of day ( $\pm 1 \mathrm{~h}$ ). In a repeated measures, crossover design, subjects were randomly assigned to order-counterbalanced conditions (see time-trials). Subjects were asked to avoid strenuous activity in the $24 \mathrm{~h}$ preceding all sessions, to avoid caffeine and food, and to maintain normal hydration in the $2 \mathrm{~h}$ before each trial. Body mass was recorded before time-trials as a proxy for hydration status.

Maximal oxygen consumption $\left(\dot{\mathrm{V}} \mathrm{O}_{2} \max \right)$

Session one involved measurement of $\dot{\mathrm{V}}_{2}$ max and familiarization with the motorized treadmill and study procedures. Subjects ran on a motorized treadmill $(\mathrm{h} / \mathrm{p} / \mathrm{cosmos}$ quasar; $\mathrm{h} / \mathrm{p} / \operatorname{cosmos}$ Sports \& Medical GmbH, Traunstein, Germany) set at a $1 \%$ gradient with continuous measurement of respiratory gas exchange (Quark C-PET, Cosmed Srl, Rome, Italy). 
Following a 5 min warm-up, subjects begin at a light intensity based on their ability. Stages lasted $3 \mathrm{~min}$ initially with $1 \mathrm{~km} \cdot \mathrm{h}^{-1}$ increments until the individual lactate turnpoint followed by $1 \mathrm{~km} \cdot \mathrm{h}^{-1}$ increments every $1 \mathrm{~min}$ until voluntary exhaustion. Heart rate was measured continuously (Polar RS400, Kempele, Finland). $\dot{\mathrm{VO}}_{2}$ max was determined as the highest value for a 10-breath rolling average. On completion, subjects were provided with an outline of sessions 2-4 but were naïve to the study's purpose and individual time-trial protocols. Subjects were familiarized with all perceptual and affective scales (see experimental sessions), exerciseanchored relative to $\dot{\mathrm{VO}}_{2}$ max test intensities (11). Subjects were also provided with a take-home sheet to familiarize with attentional focus categories.

Experimental sessions

Sessions 2-4 consisted of $3000 \mathrm{~m}$ running time-trials on a motorized treadmill. Before each time-trial, subjects were asked to complete the $3000 \mathrm{~m}$ as fast as possible and were provided either accurate or deceptive information about the objective time-trial difficulty (see time-trials). Next, subjects rated their pre-trial state motivation on a single-item scale (26) and their pre-trial mood state using the 24-item Brunel Mood Scale (27). Motivation and mood state items required subjects to respond on 5-point Likert scales ( $0=$ not at all, $4=$ extremely). Body mass (Seca 862, Hamburg, Germany) and resting blood lactate (Lactate Pro 2, Arkray Inc., Kyoto, Japan) were recorded before a standardized warm-up of 5 min running at $70 \%$ followed by $2 \mathrm{~min}$ at $80 \%$ of the maximum heart rate recorded during $\dot{\mathrm{VO}}_{2}$ max testing. Subjects were refamiliarized with the speed controls on the treadmill user terminal and practiced during each warm-up. On completion, subjects rested for 2 min before beginning the time-trial. During each time-trial subjects could control the treadmill speed by manually manipulating the speed controls on the treadmill user terminal.

Rating of perceived effort (RPE 6-20 scale (28)) and affective valence (11-point Feeling Scale (29)) were recorded verbally at $200 \mathrm{~m}$ and each $400 \mathrm{~m}$ interval thereafter. For both scales, subjects were asked to respond for how they felt over the preceding $200 \mathrm{~m}$. Heart rate was recorded continuously and averaged for the first $200 \mathrm{~m}$ and each subsequent $400 \mathrm{~m}$. At each $1000 \mathrm{~m}$ interval, subjects verbally indicated the frequency of thoughts over the previous $800 \mathrm{~m}$ for three attentional focus categories; active self-regulation, internal sensory monitoring, and outward monitoring. Subjects responded on an 11-point Likert scale $(0=$ never, $10=$ always 
(25)). All scales were projected on a screen $3.50 \mathrm{~m}$ in front of the treadmill and removed once subjects had responded. Blood lactate was also recorded immediately post-trial and attentional focus content was recounted during a brief post-trial interview (see attentional focus interview).

Time-trials

During time-trials, subjects were only able to view the distance display on the treadmill user terminal. However, a computer interface (h/p/cosmos pc software) allowed experimenters to record all pace-related data. Subjects received no other feedback or verbal encouragement. A fan was positioned at the front of the treadmill during all trials. Time-trial 1 was a baseline trial (BL) and consisted of a self-paced $3000 \mathrm{~m}$ run on a $0 \%$ gradient. Time-trials 2 and 3 were counterbalanced, randomized using a computer random number generator. Before a self-paced, known incline trial (KI), expected to be a more difficult profile, subjects were informed that the treadmill gradient would remain at $0 \%$ until the final $800 \mathrm{~m}$ when the incline (i.e. difficulty) would increase to $7 \%$ until the finish (described to subjects as a 'steep slope'). Subjects were reminded of the upcoming incline at $1800 \mathrm{~m}$. Before a self-paced, unknown incline trial (UI), expected to be less difficult, subjects were deceptively informed that the gradient would remain at $0 \%$ throughout (as during BL). At $1800 \mathrm{~m}$, however, subjects were informed that the incline would increase to $7 \%$ at $2200 \mathrm{~m}$ until the finish. A $7 \%$ gradient was selected as typical of that used to investigate the biomechanics and physiology of uphill running (30). Finally, unbeknownst to subjects, the treadmill speed was automatically reduced by $2 \mathrm{~km} \cdot \mathrm{h}^{-1}$ as the gradient increased to $7 \%$ during KI and UI. Because data during the first $2200 \mathrm{~m}$ was of primary interest, the speed reduction was introduced following pilot testing for safety reasons and was based on a spontaneous decrease in running speed of $0.295 \mathrm{~km} \cdot \mathrm{h}^{-1}$ for every $1 \%$ increase in gradient in trained runners (31). Subjects were not informed of the reduction in treadmill speed.

Post-trial attentional focus interviews

Following each time-trial, subjects completed a brief interview during which they recounted their main thoughts for active self-regulation, internal sensory monitoring, and outward monitoring during each $1000 \mathrm{~m}$ interval. To assist recall, subjects could view their individual frequency ratings for each $1000 \mathrm{~m}$ interval and category items during the interview. 
Statistical analyses

The effects of condition (KI, UI, BL) on pre-trial body mass, motivation, and mood states was analyzed using RM ANOVA. Before analysis, the running speed at each distance interval (200 m, $600 \mathrm{~m}$, etc.) during KI and UI was expressed as the percentage change relative to the speed at the equivalent interval during BL (i.e. relative running speed; RRS). Accordingly, data for each distance interval, and mean data over the first $2200 \mathrm{~m}$, the final $800 \mathrm{~m}$, and the full 3000 $\mathrm{m}$ for RRS (\%; KI and UI only), absolute running speed, perceived effort, affective valence, heart rate, and attentional focus frequency ratings (at $1000 \mathrm{~m}, 2000 \mathrm{~m}, 3000 \mathrm{~m}$ ) were analyzed using RM ANOVA. Blood lactate was analyzed using 3 (condition) X 2 (time) RM ANOVA. Greenhouse-Geisser corrections were used where sphericity assumptions were violated. Post hoc pairwise comparisons with Sidak-adjusted $P$-values were conducted where significant $F$-ratios were observed. Relationships between RRS (KI and UI only) and psychological variables, and between perceived effort, affect, and attentional focus data were investigated using bootstrapped (1000 samples) Pearson's correlations where assumptions of linearity and normality (Kolmogorov-Smirnov test) were not met. For correlations, RRS and psychological variables were averaged for the $800 \mathrm{~m}$ preceding each $1000 \mathrm{~m}$ interval (reflecting attentional focus data). Statistical significance was accepted as $P \leq .05$ for all tests. Cohen's $d$ values are provided to estimate between-trial effect sizes and interpreted as trivial $(<0.20)$, small $(0.21-0.60)$, moderate (0.61-1.20), large (1.21-2.00), and very large (2.01-4.00) (32). 95\% confidence intervals (CI) are reported for post hoc comparisons and for bootstrapped correlations (bias corrected and accelerated). Analyses were conducted using SPSS (IBM Statistics 24.0, SPSS Inc., Chicago, IL). Interview data are presented as percentage of subjects reporting attentional focus content at each $1000 \mathrm{~m}$ interval during KI and UI only.

\section{Results}

Pre-trial states

No differences were found between pre-trial states (Table 2) for body mass, potential motivation, or total mood disturbance (all $P>$.05). Individual mood states did not differ between $\mathrm{UI}$ and KI (all $P>.05)$, but tension was higher before BL than KI $(P=.026, d=0.85)$ and UI $(P$ $=.003, d=1.21)$. Vigor did not differ between UI and KI $(P=.865)$ nor between UI and BL $(P=$ $.229)$ but was higher before BL than $\mathrm{KI}(P=.038, d=0.46)$. Confusion differed between trials $F$ 
$(1.64,44.34)=4.20, P=.028, \eta_{p}^{2}=0.14$, but did not differ between any pair of trials (all $P>$ $.05)$.

During KI, pre-trial motivation correlated with RRS at $1000 \mathrm{~m}(r=.458,(.175, .687), P=$ $.014)$ and $2000 \mathrm{~m}(r=.422,(.131, .699), P=.025)$. Pre-trial vigor correlated with RRS at 1000 $\mathrm{m}(r=.423,(.153, .611), P=.025)$. No pre-trial psychological states correlated with RRS during UI (all $P>.05)$.

Time-trial performance

RRS (Fig. 1a) was slower during KI than UI after $200 \mathrm{~m}$ until the $2200 \mathrm{~m}$ distance interval (all $P \leq .009$, all $d \geq-0.43$ and $\leq-0.53$ ). Mean RRS over the first $2200 \mathrm{~m}$ was slower during KI than UI (mean difference $(\mathrm{MD})=-2.44 \% ; 95 \% \mathrm{CI},-3.92,-0.97 ; P=.002)$. In absolute terms (Fig. 1b), subjects completed the first $2200 \mathrm{~m} 13.96$ s slower during KI than UI $(P=.008)$. Exploratory analysis revealed no main order effect or condition by order interaction over the first $2200 \mathrm{~m}$ (all $P>.05$ ), but subjects who completed KI first after BL ran comparatively slower during KI ( $d=-0.58$; Fig. 1c) than those who completed UI first after BL $(d=-0.24$; Fig. 1d). RRS over the final $800 \mathrm{~m}$ (Fig. 1a) did not differ between KI and UI $(P=.854)$ but was slower over the full $3000 \mathrm{~m}$ time-trial during $\mathrm{KI}$ than $\mathrm{UI}(\mathrm{MD}=-1.62 \% ; 95 \% \mathrm{CI},-2.92,-0.32 ; P=$ .017). In absolute terms (Fig. 1b), subjects completed the full $3000 \mathrm{~m}$ time-trial $14.35 \mathrm{~s}$ slower during KI than UI $(P=.044)$. Pairwise comparisons between KI and UI are presented in Table 3.

Absolute running speed (Fig 1b) was also slower during both KI and UI than BL over the final $800 \mathrm{~m}$ (all $P<.001)$ and the full $3000 \mathrm{~m}$ (all $P<.001)$. Absolute running speed did not differ over the first $2200 \mathrm{~m}$ segment between KI and BL $(P=.978)$ nor between UI and BL $(P=$ .092) (see Supplemental Digital Content 1 for a more complete analysis, http://links.lww.com/MSS/B448).

Perceptual and affective responses

Perceived effort (Fig. 2a) over the first $2200 \mathrm{~m}$ did not differ between KI and UI nor between UI and BL (all $P>.05$ ) but was lower during KI than BL $(P=.014, d=-0.41)$. Over the final $800 \mathrm{~m}$, perceived effort did not differ between KI and UI nor between KI and BL (all $P>$ $.05)$ but was higher during UI than $\operatorname{BL}(P=.010, d=0.58)$. Perceived effort over the full $3000 \mathrm{~m}$ did not differ between conditions $(P=.200)$. Affective valence (Fig. 2b) did not differ between 
trials over the first $2200 \mathrm{~m}(P=.986)$. During the final $800 \mathrm{~m}$ affective valence did not differ between KI and UI $(P=.909)$ but was more negative during KI $(P=.008, d=-0.43)$ and UI $(P=$ $.001, d=-0.50)$ than BL. Over the full $3000 \mathrm{~m}$ affective valence did not differ between conditions $(P=.127)$. Comparisons between KI and UI are presented in Table 3.

Both perceived effort $(r=.382,(-.041, .643), P=.045)$ and affective valence $(r=-.389$, $(-.692, .089), P=.041)$ correlated with RRS at $2000 \mathrm{~m}$ during KI. No such relationships existed at $1000 \mathrm{~m}$ during KI (all $P>.05$ ) or at any distance interval during UI (all $P>.05$ ). Perceived effort was also inversely correlated with affective valence at each distance interval during KI (all $r \geq-.572$, all $P \leq .001$ ) and UI (all $r \geq-.559$, all $P \leq .002$ ) (see also Supplemental Digital Content 2, http://links.lww.com/MSS/B449).

Physiological responses

Heart rate (Fig. 2c) over the first $2200 \mathrm{~m}$ did not differ between KI and UI nor between $\mathrm{UI}$ and BL (all $P>.05)$ but was lower during KI than $\mathrm{BL}(P=.002, d=-0.35)$. Heart rate did not differ between any time-trial over the last $800 \mathrm{~m}(P=.576)$ and differences over the full $3000 \mathrm{~m}$ did not reach statistical significance $(P=.051)$. A main effect for time revealed that blood lactate (Fig. 2d) increased from pre-trial to post-trial for all time-trials $(P<.001)$. A main effect for condition revealed that blood lactate was higher in UI than BL $(P<.001)$ but did not differ between KI and UI $(P=.519)$. Finally, a condition by time interaction, $F(2,54)=8.50, P=$ $.001, \eta_{p}{ }^{2}=0.24$, revealed that blood lactate increased more after UI than BL (see Supplemental Digital Content 1, http://links.lww.com/MSS/B448).

Attentional focus

Active self-regulation was more frequent over the final $3000 \mathrm{~m}$ segment during KI than UI (MD $=1.00 ; 95 \% \mathrm{CI}, 0.11,1.89 ; P=.024, d=0.45)$ but not at $1000 \mathrm{~m}(P=.637)$ or $2000 \mathrm{~m}$ $(P=.809)$ (Fig. 3a). Active self-regulation did not differ between KI and BL nor between UI and BL (all $P>.05$ ). Internal sensory monitoring and outward monitoring frequency ratings (Fig. 3b and 3c) did not differ between time-trials at any distance interval (all $P>.05$ ).

Interview data for active self-regulatory thought content revealed that more subjects focused on pacing during KI than both UI and BL at $1000 \mathrm{~m}(82.14 \%$ vs $67.86 \%$ and $57.14 \%$ respectively) and at $2000 \mathrm{~m}$ ( $85.71 \%$ vs $67.86 \%$ and $64.29 \%$ respectively). In contrast, fewer subjects focused on other self-regulatory thoughts such as relaxing $(42.86 \%$ vs $60.71 \%$ and 
$53.57 \%$ ) over the first $1000 \mathrm{~m}$ during KI than both UI and BL. During the final $800 \mathrm{~m}$ (incline) segment fewer subjects used motivational self-talk during KI than UI (42.86\% vs $71.43 \%)$. In contrast, more subjects focused on relaxing ( $35.71 \%$ vs $17.86 \%)$ and chunking (42.86\% vs $28.57 \%$ ) during the final $800 \mathrm{~m}$ of KI than UI (see Supplemental Digital Content 3 for all attentional focus content, http://links.lww.com/MSS/B450).

Internal sensory monitoring and outward monitoring thought content did not differ greatly between time-trials. During KI and UI most subjects focused on breathing and movement form at $1000 \mathrm{~m}$ and $2000 \mathrm{~m}$ and breathing and overall effort/feel over the final $800 \mathrm{~m}$ segment. Outward monitoring during time-trials was predominantly on the distance display.

Finally, during KI perceived effort correlated with both internal sensory monitoring and outward monitoring at $2000 \mathrm{~m}(r=.401,(.064, .680), P=.034$, and $r=.376,(-.070, .685), P=$ .048 respectively $)$ and $3000 \mathrm{~m}(r=.452,(.115, .742), P=.016$, and $r=.467,(.167, .729), P=$ .012 respectively). During UI, perceived effort correlated with internal sensory monitoring only at $2000 \mathrm{~m}(r=.374,(-.260, .837), P=.050)$ and $3000 \mathrm{~m}(r=.431,(.044, .714), P=.022)$. No relationships were found between perceived effort and active self-regulation during time-trials (all $P>$.05). Relationships between attentional focus categories are presented in Supplemental Digital Content 2, http://links.lww.com/MSS/B449.

\section{Discussion}

This was the first study to investigate the effects of anticipated task difficulty on pacing, psychological, and physiological responses during endurance activity. In agreement with the first hypothesis, a novel finding was that subjects ran $2.44 \%$ slower over the first $2200 \mathrm{~m}$ of a $3000 \mathrm{~m}$ time-trial anticipated to become more difficult (known incline; KI) in comparison with a similar, equidistant time-trial deceptively expected to be less difficult (unknown incline; UI) (Fig. 1a-b). The difference in running speed between time-trials, expressed as the percentage change relative to a baseline (BL) time-trial (relative running speed; RRS) was larger than the coefficient of variation $(1.50 \%)$ and the smallest worthwhile change $(0.50 \%)$ suggested for shorter endurance events $(<12,000 \mathrm{~m})(33)$. As such, the slower speed during KI than UI represents a real and substantial difference in performance. In spite of this, perceived effort, affective valence, heart rate, and blood lactate did not differ between KI and UI (Fig. 2a-d). The similar ratings of 
perceived effort between KI and UI time-trials supports the second hypothesis in that the reduction in running speed did not result in a lower perception of effort.

The findings of this study add to theoretical understandings of factors that impact on pace-regulation during endurance activity. The slower running speed during KI than UI suggests that in addition to knowledge of task distance/duration $(15,16,18)$ the anticipated difficulty of the task also influences pace-related decision-making and endurance performance. In agreement with existing perspectives $(4,9,10,12)$ there was evidence that previous task experience modulated pacing during time-trials. Specifically, although no order effect was found, a larger reduction in RRS during the first $2200 \mathrm{~m}$ of KI was noted for those who completed the KI timetrial first after BL (Fig. 1c) in comparison with those who completed the KI time-trial last (Fig. 1d). As such, these findings support assertions that an athlete's pacing strategy relates to the likely demands of an activity $(1,2,14)$ and greater demand uncertainty can result in a larger reduction in work rate during task performance $(3,6)$.

Relationships between RRS and subjects' psychological responses provide further insight into factors determining pacing during time-trials. Specifically, RRS during KI was positively associated with pre-trial motivation (at $1000 \mathrm{~m}$ and $2000 \mathrm{~m}$ ), vigor (at $1000 \mathrm{~m}$ ), and within-trial perceived effort (at $2000 \mathrm{~m}$ ). No such relationships existed during UI. These data suggest that the initial running speed during KI was influenced by subjects' pre-trial motivation and successrelated drives $(4,5,9)$. More so, motivated behaviour is characterized by higher vigor and the exertion of effort during goal-directed action (34). Consequently, perception of effort also appeared to play an important regulatory role in pace-related decision-making during KI $(4,5,9,14)$. It has been suggested that the experience of effort provides important information about the difficulty of a task and a need to conserve energy for future activity (35). As such, the slower initial speed during KI may reflect an elevated perception of task-related difficulty during that time-trial. Coupled with more subjects reporting a self-regulatory focus on pacing, the findings suggest a consciously aware, effort-based decision to reduce pace and conserve energy during KI (2-4,9,35). In contrast, the faster initial running speed during UI, unrelated to pre-trial motivation or perceived effort and completed with a reduced focus on pacing, suggests a more automated, sub-aware form of regulatory control (2). This may indicate that subjects followed a pre-planned pacing strategy during UI, unaffected by expectations of increasing task difficulty and perceived need to conserve energy $(3,23)$. 
Similar to perceived effort, affective valence did not differ between time-trials despite the slower running speed during KI (Fig. 2b). A negative relationship was observed between affective valence and RRS during the initial stages of KI, however, and between perceived effort and affective valence throughout time-trials. These findings support contentions that affective state may also play a primary and/or mediatory role in pace-regulation during endurance activity $(7,13)$. Relevant to the present context, anticipated affective responses also impact on behavioral decisions and the slower initial speed during KI may further reflect a pre-emptive pacing tactic to minimize reductions in hedonic state over the final $800 \mathrm{~m}$ (36). Collectively, the findings suggest that alongside a consciously aware attempt to regulate pacing behaviour, effort- and affect-based heuristics (i.e. mental 'short-cuts' used to make decisions during situations of increased complexity or uncertainty) may have influenced pace-related decision-making during KI $(3,6,7,37)$. As such, heuristic decision-making may have allowed subjects solve a pacing conundrum during KI resulting from increased task uncertainty and a perception that the risks of running faster (e.g. feeling very bad, having to stop) outweighed any perceived benefits $(8,35-$ 37).

In addition to an increased focus on pacing during $\mathrm{KI}$, other attentional focus findings also provided some important insights. During the initial stages of UI, for example, more subjects reported focusing on other self-regulatory thoughts such as relaxing. Relaxation has been shown to improve movement economy during endurance activity $(17,38)$ and may account in part for the similar physiological responses during UI as KI, despite a faster running speed. Furthermore, associations between perceived effort and both internal sensory monitoring (KI and UI) and outward monitoring (KI only) add a more nuanced understanding of the relationship between effort perceptions and associative thought content when manipulating task-related variables $(15,16,18)$. Specifically, during both KI and UI, the data suggest that effort perceptions were positively associated with internal sensory monitoring (24). In addition, the relationship between effort perceptions and outward monitoring during KI strengthens our contention that pace-regulation during KI resulted from a consciously aware decision-making processes that incorporated a focus on the time-trial distance information. Finally, during UI many more subjects reported using motivational self-statements, such as 'keep it going' or 'you've done this before', to complete the unexpected $800 \mathrm{~m}$ incline. Motivational self-talk has been shown to improve endurance performance (39) and is typically used in contexts where the activity feels 
more challenging yet maintaining a desired level of performance is a priority (23). As such, subjects' self-talk during UI may reflect a facilitative, goal-directed response to maintain goalpursuit (i.e. complete the time-trial as quickly as possible) and avoid task-disengagement (i.e. stopping or slowing excessively) following the unexpected increase in task difficulty $(7,23)$.

In spite of the findings, some limitations should be acknowledged. Because time-trials were completed on a motorized treadmill and subjects were required to manually manipulate the treadmill pace controls, the findings may have reduced ecological validity (1). This may be particularly relevant for attentional focus outcomes (e.g. outward monitoring) and subsequent pace-related decision-making in more naturalistic settings. The reduction in running speed enforced by experimenters during the final $800 \mathrm{~m}$ incline segment of KI and UI should also be highlighted and may have impacted on subjects pacing tactics over the final $800 \mathrm{~m}$. However, it is noteworthy that the majority of subjects did not indicate an awareness of this intervention as most subjects simultaneously attempted to slow the treadmill using the treadmill speed controls at this point. Following time-trials, only four subjects reported any awareness of the experimenter intervention but described noticing a change in the noise of the treadmill motor rather than a change in treadmill speed. These subjects were deceptively informed that the change in treadmill motor noise was normal when the treadmill incline increased.

Collection of psychological data during time-trials may also have impacted on subjects' usual attentional processes. However, data collection was consistent between time-trials and subjects responded quickly $(\sim 10 \mathrm{~s})$ at each distance interval, minimizing intrusiveness and possible interference. Furthermore, collecting attentional focus frequency ratings at $1000 \mathrm{~m}$ intervals was important to inform post-time-trial interviews and overcome delayed recall of within-trial attentional focus content (17). Finally, the small number of female subjects $(n=5)$ should also be considered. Although not of primary interest in this study, exploratory analyses revealed no differences in pacing, psychological, or physiological outcomes between genders, although males engaged in more active self-regulation during UI. Given that male and female runners may pace longer-distance athletic competitions differently (40), future researchers may wish to consider potential gender influences during investigations of pace-related decisionmaking during endurance activity. 


\section{Conclusions and applied recommendations}

This was the first study to investigate the effects of anticipated task difficulty on pacing, psychological, and physiological responses during endurance activity. The main findings were that subjects ran slower when they anticipated a $3000 \mathrm{~m}$ time-trial would become more difficult in comparison with a time-trial deceptively expected to be less difficult. Despite this slower running speed, perceptual, affective, and physiological responses did not differ between timetrials. From a theoretical perspective, this study adds to our awareness and understanding of factors that influence pacing and endurance performance. More so, the findings highlight a specific context (i.e. anticipation of task difficulty) that may influence the regulatory processes underpinning pace-related decision-making. Based on the findings, some important recommendations for endurance athletes and coaches can be suggested. Firstly, the reduced speed during KI appeared to result from increased demand uncertainty. However, previous experience reduced this negative impact for those who completed the KI time-trial last. As such, adequate familiarization with route elevations or other challenges (e.g. terrain (20)) before performance may help to reduce uncertainty and optimize pacing. Other self-regulatory cognitive strategies, such as chunking (i.e. mentally breaking a longer distance activity into smaller segments) and strategically setting more proximal pace-related sub-goals $(23,24)$ may also reduce the deleterious effects of anticipated increases in task difficulty. Finally, the greater use of motivational self-talk during the final $800 \mathrm{~m}$ of UI emphasizes the importance of employing situationally-appropriate cognitive strategies to maintain goal-pursuit $(7,23)$ during the challenging and often unexpected events that occur during endurance activity. 


\section{Conflicts of interest, source of funding, and acknowledgements}

This study received no sources of funding. The authors have no conflicts of interest to report. The results do not constitute endorsement by the ACSM and are presented clearly, honestly, and without fabrication, falsification, or inappropriate data manipulation. The authors wish to thank Noel McLaughlin, Aimee Gorman, Meghann McKeever, Nazareth Jorvinah, and Carla Hamilton for their invaluable assistance during data collection. We also thank Patrick Lynch and the Dingle Marathon, Ireland for providing the inspiration for this study. 


\section{References}

1. Smits BL, Pepping GJ, Hettinga FJ. Pacing and decision making in sport and exercise: the roles of perception and action in the regulation of exercise intensity. Sports Med. 2014;44(6):763-75.

2. Edwards AM, Polman RCJ. Pacing and awareness: brain regulation of physical activity. Sports Med. 2013;43(11):1057-64.

3. Renfree A, Martin L, Micklewright D, St Clair Gibson A. Application of decision-making theory to the regulation of muscular work rate during self-paced competitive endurance activity. Sports Med. 2014;44(2):147-58.

4. Pageaux B. The psychobiological model of endurance performance: an effort-based decisionmaking theory to explain self-paced endurance performance. Sports Med. 2014);44(9):131920.

5. St Clair Gibson A, Swart J, Tucker R. The interaction of psychological and physiological homeostatic drives and role of general control principles in the regulation of physiological systems, exercise and the fatigue process - The Integrative Governor theory. Eur J Sport Sci. 2018;18(1):25-36.

6. Micklewright D, Kegerreis S, Raglin J, Hettinga, FJ. Will the conscious-subconscious pacing quagmire help elucidate the mechanisms of self-paced exercise? New opportunities in dual process theory and process tracing methods. Sports Med. 2017;47:1231-9.

7. Venhorst A, Micklewright D, Noakes TD. Towards a three-dimensional framework of centrally regulated and goal-directed exercise behaviour: a narrative review. Br J Sports Med. 2018;52(15):957-66.

8. Micklewright D, Parry D, Robinson $\mathrm{T}$, et al. Risk perception influences athletic pacing strategy. Med Sci Sports Exerc. 2015;47(5):1026-37.

9. Marcora SM. Counterpoint: afferent feedback from fatigued locomotor muscles is not an important determinant of endurance exercise performance. J Appl Physiol. 2010;108:454-6. 
10. St Clair Gibson A, Noakes TD. Evidence for complex system integration and dynamic neural regulation of skeletal muscle recruitment during exercise in humans. Br J Sports Med. 2004;38(6):797-806.

11. Pageaux B. Perception of effort in exercise science: definition, measurement and perspectives. Eur J Sport Sci. 2016;16(8):885-94.

12. Micklewright D, Papadopoulou E, Swart J, Noakes, TD. Previous experience influences pacing during $20 \mathrm{~km}$ time trial cycling. Br J Sports Med. 2010;44(13):952-60.

13. Renfree A, West J, Corbett M, Rhoden C, St Clair Gibson A. Complex interplay between determinants of pacing and performance during $20-\mathrm{km}$ cycle time trials. Int J Sports Physiol Perform. 2010;7(2):121-9.

14. Ulmer HV. Concept of an extracellular regulation of muscular metabolic rate during heavy exercise in humans by psychophysiological feedback. Experientia. 1996;52(5):416-20.

15. Rejeski WJ, Ribisl PM. Expected task duration and perceived effort: an attributional analysis. J Sport Psychol. 1980:2(3):227-36.

16. Baden DA, Warwick-Evans L, Lakomy J. Am I nearly there? The effect of anticipated running distance on perceived exertion and attentional focus. J Sport Ex Psychol. 2004;26(2):215-31.

17. Brick N, MacIntyre T, Campbell M. Attentional focus in endurance activity: new paradigms and future directions. Int Rev Sport Exerc Psychol. 2014;7(1):106-34.

18. Baden DA, McLean TL, Tucker R, Noakes TD, St Clair Gibson A. Effect of anticipation during unknown or unexpected exercise duration on rating of perceived exertion, affect, and physiological function. Br J Sports Med. 2005;39(10):742-746.

19. Faulkner J, Parfitt G, Eston R. The rating of perceived exertion during competitive running scales with time. Psychophysiology. 2008;45(6):1077-85.

20. Reese RJ. Just how bad is Heartbreak Hill? (Internet). Runnersworld.com; 2013 Apr 15 (cited 2018 July 30). Available from: https://www.runnersworld.com/run-the-numbers/justhow-bad-is-heartbreak-hill 
21. Zamparo P, Perini R, Orizio C, Sacher M, Ferretti G. The energy cost of walking or running on sand. Eur J Physiol Occup Physiol. 1992;65(2):183-7.

22. Davies CTM. Effects of wind assistance and resistance on the forward motion of a runner. $J$ Appl Physiol Respir Environ Exerc Physiol. 1980;48(4):702-9.

23. Brick N, MacIntyre T, Campbell M. Metacognitive processes in the self-regulation of performance in elite endurance runners. Psychol Sport Exerc. 2015;19:1-9.

24. Brick NE, Campbell MJ, Metcalfe RS, Mair JL, MacIntyre TE. Altering pace control and pace regulation: attentional focus effects during running. Med Sci Sports Exerc. 2016;48(5):879-86.

25. de Pauw K, Roelands B, Cheung SS, de Geus B, Rietjens G, Meeusen R. Guidelines to classify subject groups in sport-science research. Int $J$ Sports Physiol Perform. 2013;8(2):111-122.

26. Matthews G, Campbell SE, Falconer S. Assessment of motivational states in performance environments. Proc Hum Fact Ergon Soc Annu Meeting. 2001;45(13):906-10.

27. Terry PC, Lane AM, Fogarty GJ. Construct validity of the Profile of Mood State Adolescents for use with adults. Psychol Sport Exerc. 2003;4(2):125-39.

28. Borg GA. Psychophysical bases of perceived exertion. Med Sci Sports Exerc. $1982 ; 14(5): 377-81$.

29. Hardy CJ, Rejeski WJ. (1989). Not what, but how one feels: The measurement of affect during exercise. J Sport Exerc Psychol. 1989;11(3):304-317.

30. Vernillo G, Giandolini M, Edwards WB, et al. Biomechanics and physiology of uphill and downhill running. Sports Med. 2017;47(4):615-29.

31. Townshend AD, Worringham CJ, Stewart I. Spontaneous pacing during overground hill running. Med Sci Sports Exerc. 2010;42(1):160-9.

32. Hopkins WG, Marshall SW, Batterham AM, Hanin J. Progressive statistics for studies in sports medicine and exercise science. Med Sci Sports Exerc. 2009;41(1):3-13

33. Hopkins WG, Hewson DJ. Variability of competitive perforance of distance runners. Med Sci Sports Exerc. 2001;33(9):1588-92. 
34. Salamone JD, Correa M, Yohn SE, et al. Behavioral activation, effort-based choice, and elasticity of demand for motivational stimuli: basic and translational neuroscience approaches. Motivation Science. 2017;3(3):208-29.

35. Preston J, Wegner, DM. Elbow grease: When action feels like work. In Morsella E, Bargh JA, P. M. Gollwitzer PM. editors Oxford handbook of human action. Oxford, UK: Oxford University Press; 2009. p. 569-86.

36. Mellers B, Schwartz A, Ritov I. Emotion-based choice. J Exp Psychol Gen. 1999;128(3):332-45.

37. Finucane ML, Alhakami A, Slovic P, Johnson SM. The affect heuristic in judgements of risks and benefits. J Behav Dec Making. 2000;13(1):1-17.

38. Caird SJ, McKenzie AD, Sleivert GG. Biofeedback and relaxation techniques improve running economy in sub-elite long distance runners. Med Sci Sports Exerc. 1999;31(5):71722.

39. Blanchfield AW, Hardy J, de Morree HM, Staino W, Marcora SM. Talking yourself out of exhaustion: the effects of self-talk on endurance performance. Med Sci Sport Exerc. 2014;46(5):998-1007.

40. Hanley B. Pacing, packing and sex-based differences in Olympic and IAAF World Championship marathons. J Sports Sci. 2016;34(17):1675-81. 


\section{Figure and Tablecaptions}

Fig. 1. Relative running speed (RRS) (a), absolute running speed (b), RRS for subjects in KI then UI order (c), and RRS for subjects in UI then KI order (d) during time-trials. Error bars illustrate SD. Symbols denote main effect of condition: (*) KI significantly different from UI, (§) both KI and UI significantly different from BL.

Fig. 2. Perceived effort (a), affective valence (b), heart rate (c), and blood lactate (d) responses during time-trials. Error bars illustrate SD. BL shown for comparison. Symbols denote main effect of condition: (\#) KI significantly different from BL, $\left({ }^{\wedge}\right) \mathrm{UI}$ significantly different from BL, (§) both KI and UI significantly different from BL.

Fig. 3. Attentional focus frequency ratings for active self-regulation (a), internal sensory monitoring (b), and outward monitoring (c) responses during time-trials. Error bars illustrate SD. BL shown for comparison (see also Supplemental Digital Content 1, http://links.lww.com/MSS/B448). Symbols denote main effect of condition: (*) KI significantly different from UI.

Table 1. Demographic and training characteristics of subjects $(n=28)$.

Table 2. Pre-trial body mass, motivation, and mood states.

Table 3. Time-trial performance, psychological, and physiological responses during KI and UI.

Supplemental Digital Content (SDC) 1. Distance interval analyses for KI, UI and BL.

Supplemental Digital Content (SDC) 2. Correlations between variables.

Supplemental Digital Content (SDC) 3. Attentional focus data. 


\section{Figure 1}

a
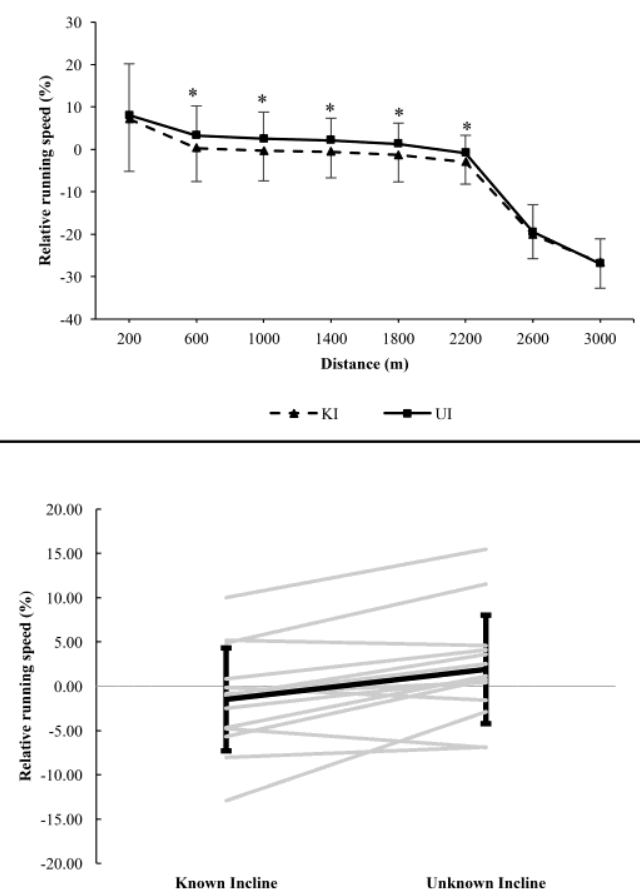

b

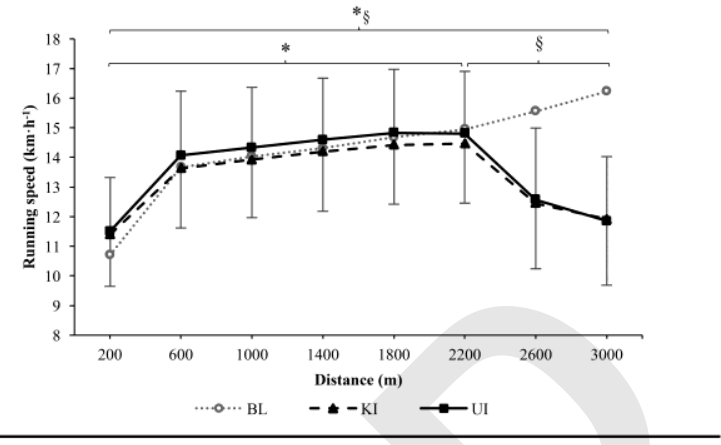

d

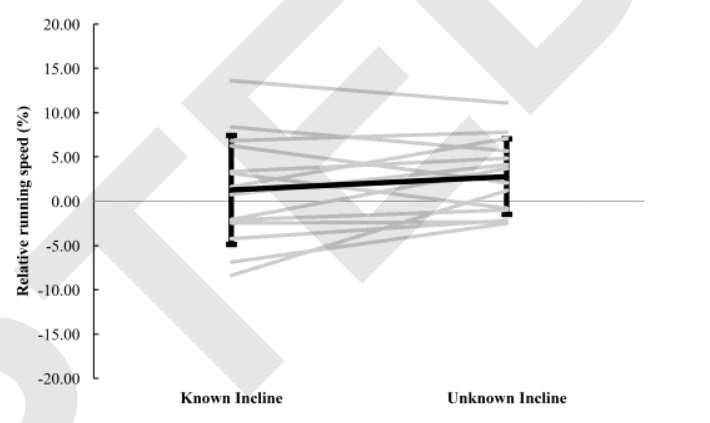


Figure 2

a

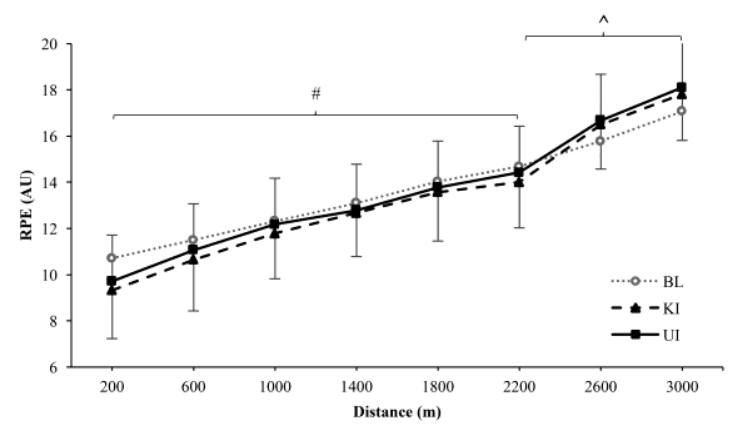

C

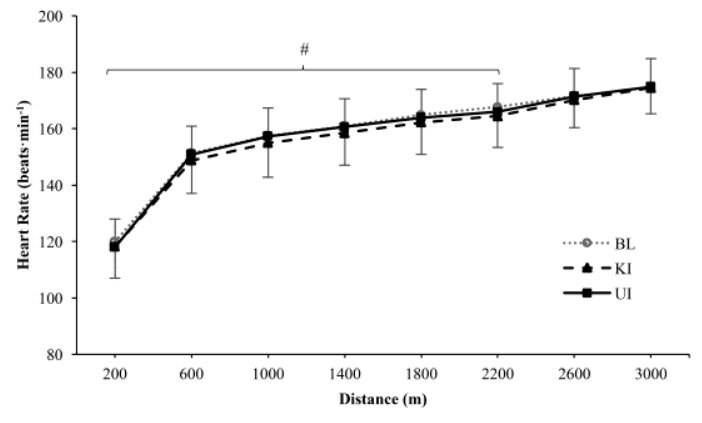

b

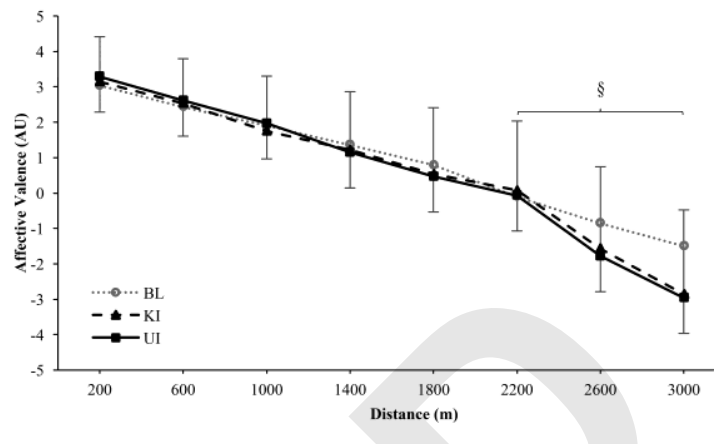

d

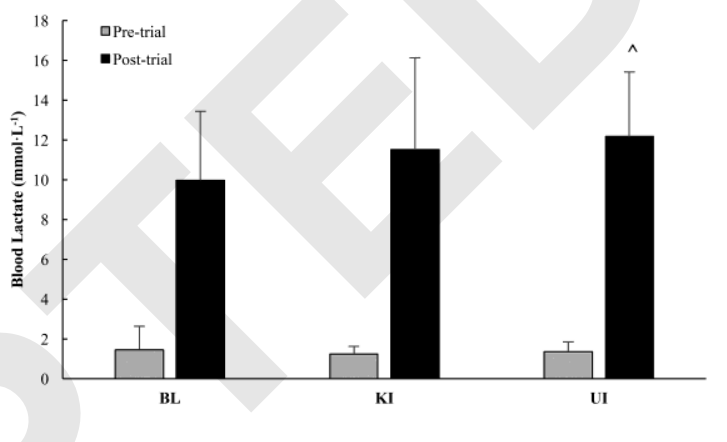




\section{Figure 3}

a

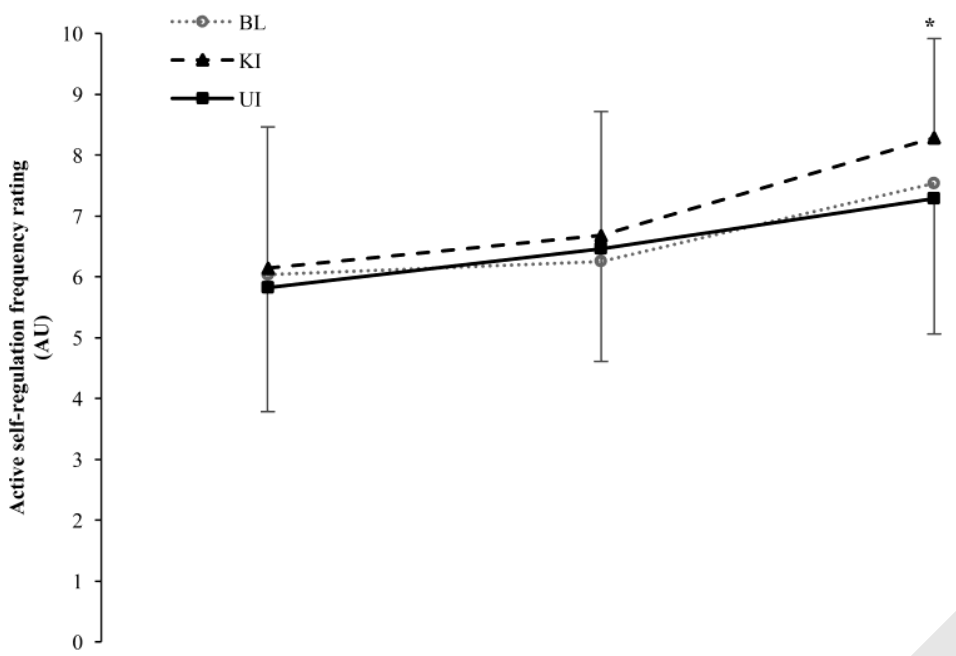

b

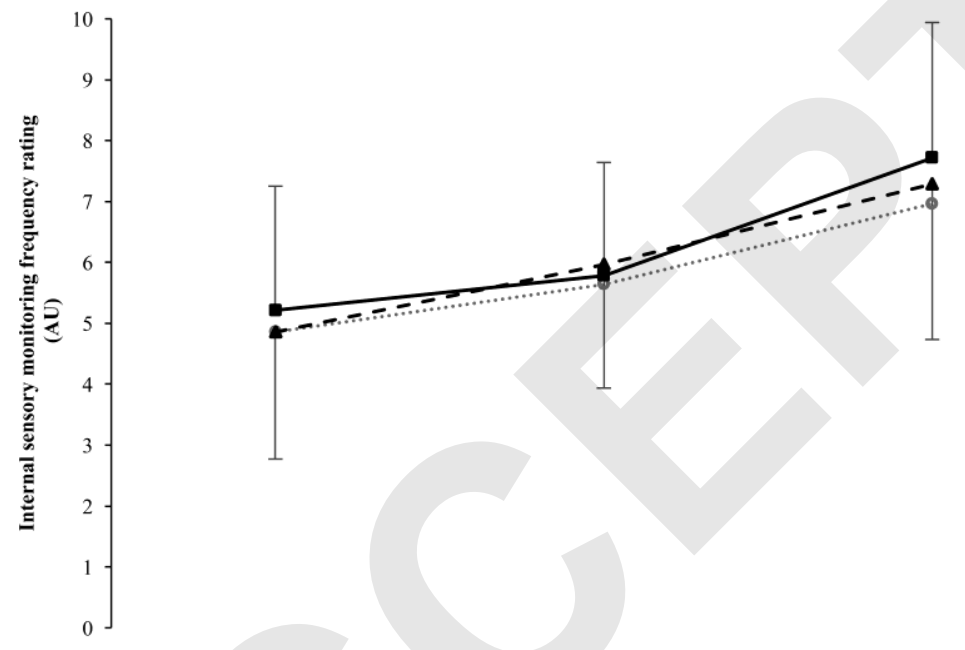

c

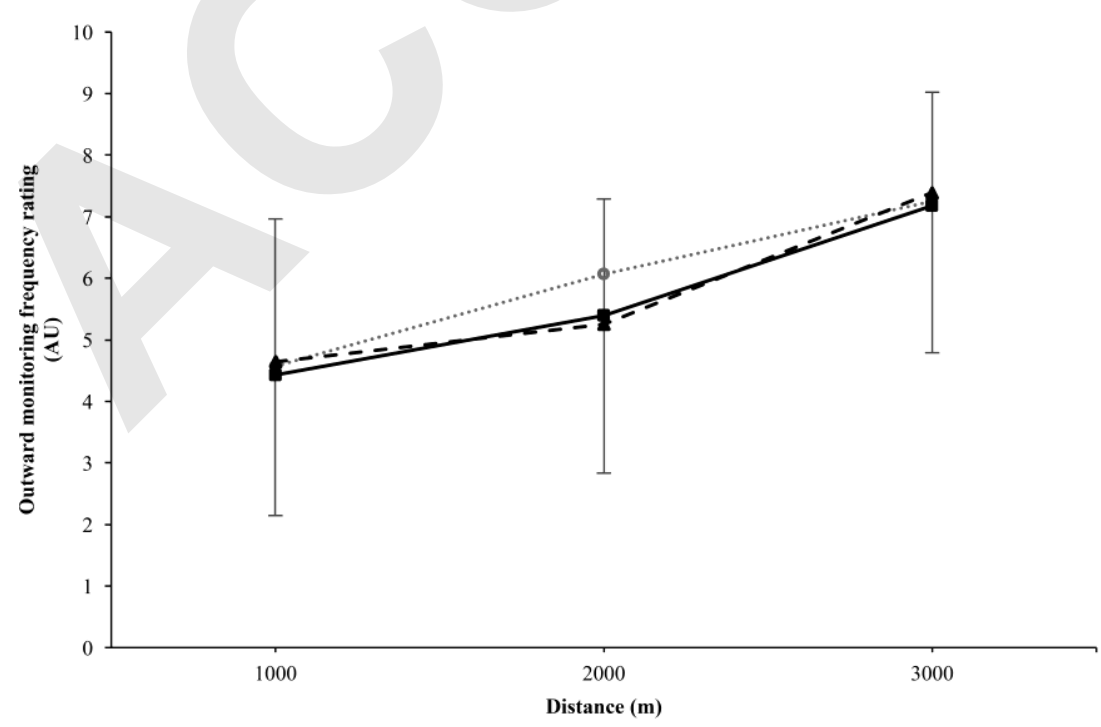


Table 1. Demographic and training characteristics of subjects $(n=28)$.

\begin{tabular}{|c|c|}
\hline Variable & \\
\hline Age (yr) & $40.52 \pm 9.43$ \\
\hline Gender & $23 \mathrm{M}, 5 \mathrm{~F}$ \\
\hline Body Mass (kg; Session 1) & $74.29 \pm 10.13$ \\
\hline Height (m) & $1.73 \pm 0.08$ \\
\hline$\dot{\mathbf{V}} \mathrm{O}_{2} \max \left(\mathrm{mL} \cdot \mathrm{kg}^{-1} \cdot \min ^{-1}\right)$ & $51.58 \pm 7.40$ \\
\hline $\operatorname{Men}\left(\mathbf{m L} \cdot \mathbf{k g}^{-1} \cdot \mathbf{m i n}^{-1}\right)$ & $53.24 \pm 6.68$ \\
\hline Women $\left(\mathrm{mL} \cdot \mathrm{kg}^{-1} \cdot \mathrm{min}^{-1}\right)$ & $43.94 \pm 5.96$ \\
\hline Running experience (yr) & $9.27 \pm 7.92$ \\
\hline Training volume $\left(\mathbf{k m} \cdot \mathbf{w k}^{-1}\right)$ & $59.76 \pm 26.05$ \\
\hline Training frequency $\left(d \cdot w^{-1}\right)$ & $4.45 \pm 1.51$ \\
\hline
\end{tabular}


Table 2. Pre-trial body mass, motivation, and mood states.

Mood State Variables

\section{Bod}

\begin{tabular}{|c|c|c|c|c|c|c|c|c|c|}
\hline & $\begin{array}{c}\mathbf{y} \\
\text { Mas } \\
\text { s } \\
\text { (kg) }\end{array}$ & $\begin{array}{c}\text { Motivatio } \\
\mathbf{n}\end{array}$ & $\begin{array}{c}\text { TM } \\
\text { D }\end{array}$ & $\begin{array}{c}\text { Tensio } \\
\text { n }\end{array}$ & $\begin{array}{c}\text { Depressio } \\
\mathbf{n}\end{array}$ & $\begin{array}{c}\text { Ange } \\
\mathbf{r}\end{array}$ & $\begin{array}{c}\text { Fatigu } \\
\text { e }\end{array}$ & $\begin{array}{c}\text { Confusio } \\
\mathbf{n}\end{array}$ & $\begin{array}{c}\text { Vigo } \\
\mathbf{r}\end{array}$ \\
\hline $\begin{array}{l}\text { B } \\
\text { L }\end{array}$ & $\begin{array}{c}74.3 \\
6 \pm \\
1.46\end{array}$ & $2.79 \pm 0.96$ & $\begin{array}{c}-4.68 \\
\pm \\
6.07\end{array}$ & $\begin{array}{c}2.07 \pm \\
2.31\end{array}$ & 1 & $\begin{array}{c}0.21 \pm \\
0.57\end{array}$ & $\begin{array}{c}2.25 \pm \\
2.22\end{array}$ & $\begin{array}{c}0.43 \pm \\
0.69\end{array}$ & $\begin{array}{c}9.82 \\
\pm \\
2.68\end{array}$ \\
\hline KI & $\begin{array}{c}74.0 \\
4 \pm \\
9.85\end{array}$ & $2.71 \pm 0.90$ & $\begin{array}{c}-4.71 \\
\pm \\
5.29\end{array}$ & $\begin{array}{l}1.04 \pm \\
1.23^{\S}\end{array}$ & $0.14 \pm 0.52$ & $\begin{array}{c}0.32 \pm \\
0.94\end{array}$ & $\begin{array}{c}1.89 \pm \\
2.08\end{array}$ & $\begin{array}{c}0.18 \pm \\
0.48\end{array}$ & $\begin{array}{c}8.29 \\
\pm \\
3.34^{\#}\end{array}$ \\
\hline UI & $\begin{array}{c}73.9 \\
4 \pm \\
9.82\end{array}$ & $3.04 \pm 0.64$ & $\begin{array}{c}-5.71 \\
\pm \\
4.23\end{array}$ & $\begin{array}{c}0.89 \pm \\
1.47^{\S}\end{array}$ & $0.00 \pm 0.00$ & $\begin{array}{c}0.00 \pm \\
0.00\end{array}$ & $\begin{array}{c}1.96 \pm \\
2.05\end{array}$ & $\begin{array}{c}0.18 \pm \\
0.39\end{array}$ & $\begin{array}{c}8.75 \\
\pm \\
2.86\end{array}$ \\
\hline
\end{tabular}

Data presented as mean \pm standard deviation $(S D)$ for Baseline, (BL), known incline (KI) and unknown incline (UI) time-trials.

Total Mood Disturbance (TMD) is calculated as the sum of all negative mood states minus the score for vigor. A lower score indicates a more positive mood state.

Symbols denote:. ${ }^{\S} \mathrm{KI}$ and UI both significantly different from BL. ${ }^{\text {K }}$ KI significantly different from BL. 
Table 3. Time-trial performance, psychological, and physiological responses during KI and UI.

\begin{tabular}{lllll}
\hline Measure & KI & UI & $P$ & $\begin{array}{c}\text { Effect } \\
\text { size }(d)\end{array}$
\end{tabular}

\section{Time-trial performance}

Relative speed full 3000 m (\%)

$\begin{array}{cccc}-7.09 \pm 4.62^{*} & -5.48 \pm 3.66 & .017 & -0.44 \\ -0.10 \pm 6.04^{*} & 2.34 \pm 5.20 & .002 & -0.47 \\ -23.54 \pm 5.49 & -23.37 \pm 5.53 & .854 & -0.03 \\ 829.71 \pm & 815.36 \pm 127.13 & .044 & 0.11 \\ 127.64^{*} & & & \\ 585.21 \pm 86.94^{*} & 571.25 \pm 87.41 & .008 & 0.16 \\ 244.50 \pm 45.06 & 244.11 \pm 45.57 & .995 & 0.01\end{array}$

\section{Psychological responses}

Perceived effort first $2200 \mathrm{~m}$

$12.00 \pm 1.67$

$12.33 \pm 1.82$

.475

$-0.18$

(AU)

Perceived effort final $800 \mathrm{~m}(\mathrm{AU})$

$17.16 \pm 1.95$

$17.39 \pm 1.89$

.823

$-0.12$

Affective Valence first $2200 \mathrm{~m}$

$$
1.54 \pm 1.48
$$

$1.57 \pm 1.32$

.998

$-0.02$

(AU)

Affective Valence final $800 \mathrm{~m}$

$-2.21 \pm 2.43$

$-2.38 \pm 2.30$

.909

0.07

(AU)

\section{Physiological responses}

Heart rate first $2200 \mathrm{~m}\left(\mathrm{~b} \cdot \mathrm{min}^{-1}\right)$

$$
\begin{array}{lcccc}
\text { Heart rate first } 2200 \mathrm{~m}\left(\mathrm{~b} \cdot \mathrm{min}^{-1}\right) & 151.16 \pm 11.82 & 152.79 \pm 11.12 & .227 & -0.15 \\
\text { Heart rate final } 800 \mathrm{~m}\left(\mathrm{~b} \cdot \mathrm{min}^{-1}\right) & 172.34 \pm 9.85 & 173.10 \pm 9.37 & .712 & -0.08 \\
\text { Pre-trial blood lactate }\left(\mathrm{mmol} \cdot \mathrm{L}^{-1}\right) & 1.25 \pm 0.38 & 1.36 \pm 0.49 & .568 & -0.22 \\
\text { Post-trial blood lactate }\left(\mathrm{mmol} \cdot \mathrm{L}^{-}\right. & 11.50 \pm 4.63 & 12.17 \pm 3.25 & .639 & -0.21
\end{array}
$$$$
\begin{array}{lllll}
\text { Pre-trial blood lactate }\left(\mathrm{mmol} \cdot \mathrm{L}^{-1}\right) & 1.25 \pm 0.38 & 1.36 \pm 0.49 & .568 & -0.22
\end{array}
$$$$
\left.{ }^{1}\right)
$$

Data presented as mean \pm standard deviation (SD). $P$-values and effect sizes $(d)$ based on pairwise comparisons between KI and UI time-trials. Symbols denote: * significant difference between KI and UI. AU: Arbitrary Units. Psychological and physiological responses represent mean values over $2200 \mathrm{~m}$ and $800 \mathrm{~m}$ segments. 
Figure SDC1a. Analysis of relative running speed data at each distance interval

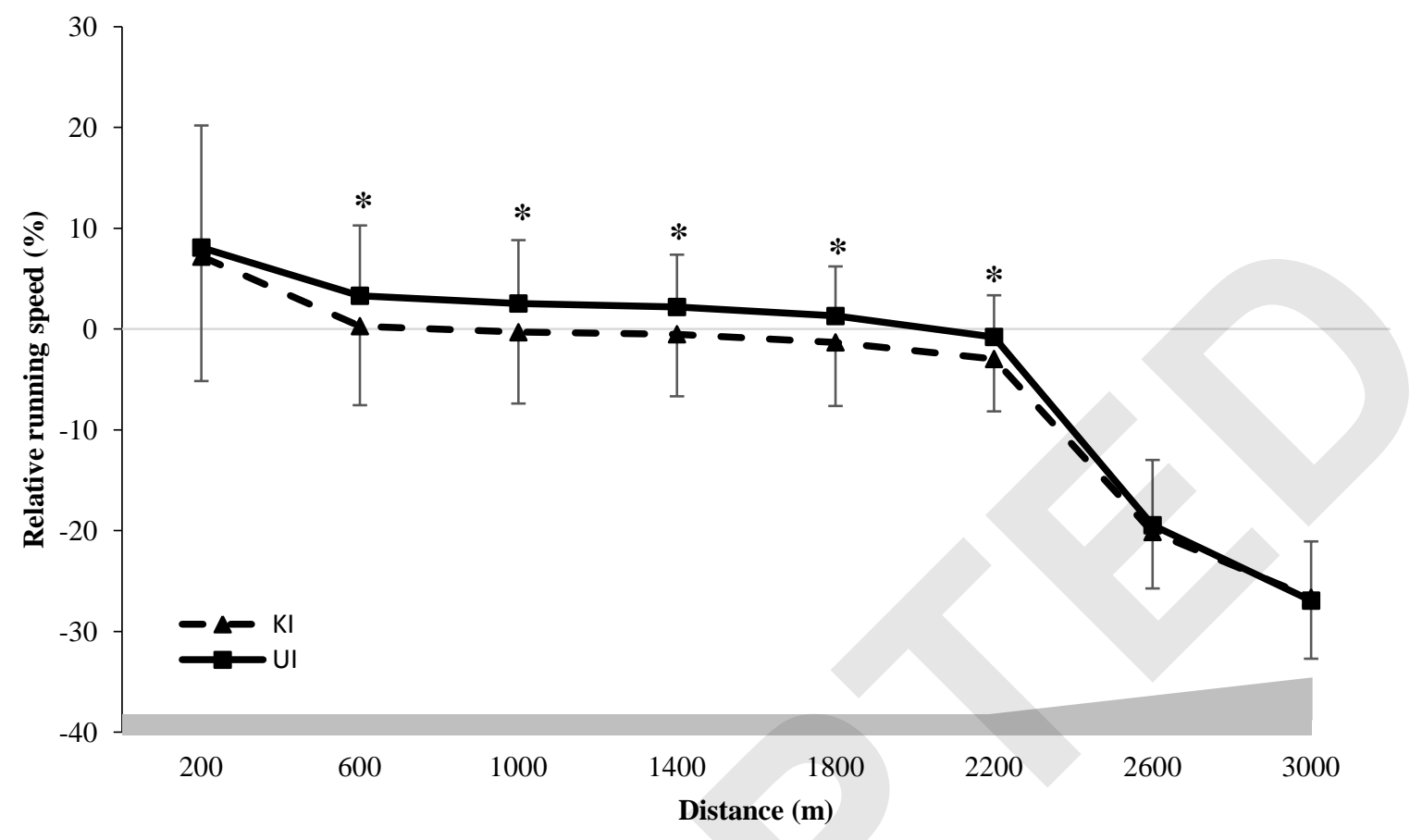

BL: Baseline time-trial; KI: Known incline time-trial; UI: Unknown incline time-trial. Symbols denote: * KI significantly different from UI.

Expressed relative to distance interval running speed during BL, relative running speed (RRS) was slower during $\mathrm{KI}$ than UI at $\mathbf{6 0 0} \mathbf{m}(\mathrm{MD}=-3.02 \%$; $95 \% \mathrm{CI},-5.23,-0.80 ; P=.009, d=-$ $0.43), 1000 \mathrm{~m}(\mathrm{MD}=-2.85 \% ; 95 \% \mathrm{CI},-4.66,-1.04 ; P=.003, d=-0.45), 1400 \mathrm{~m}(\mathrm{MD}=-$ 2.70\%; 95\% CI, -4.26, -1.15; $P=.001, d=-0.52), 1800$ m (MD = -2.61\%; 95\% CI, -4.12, -1.10; $P=.001, d=-0.53)$, and $2200 \mathbf{m}(\mathrm{MD}=-2.19 \% ; 95 \% \mathrm{CI},-3.76,-0.61 ; P=.008, d=-0.53)$. 
Figure SDC1b. Analysis of absolute running speed data at each distance interval

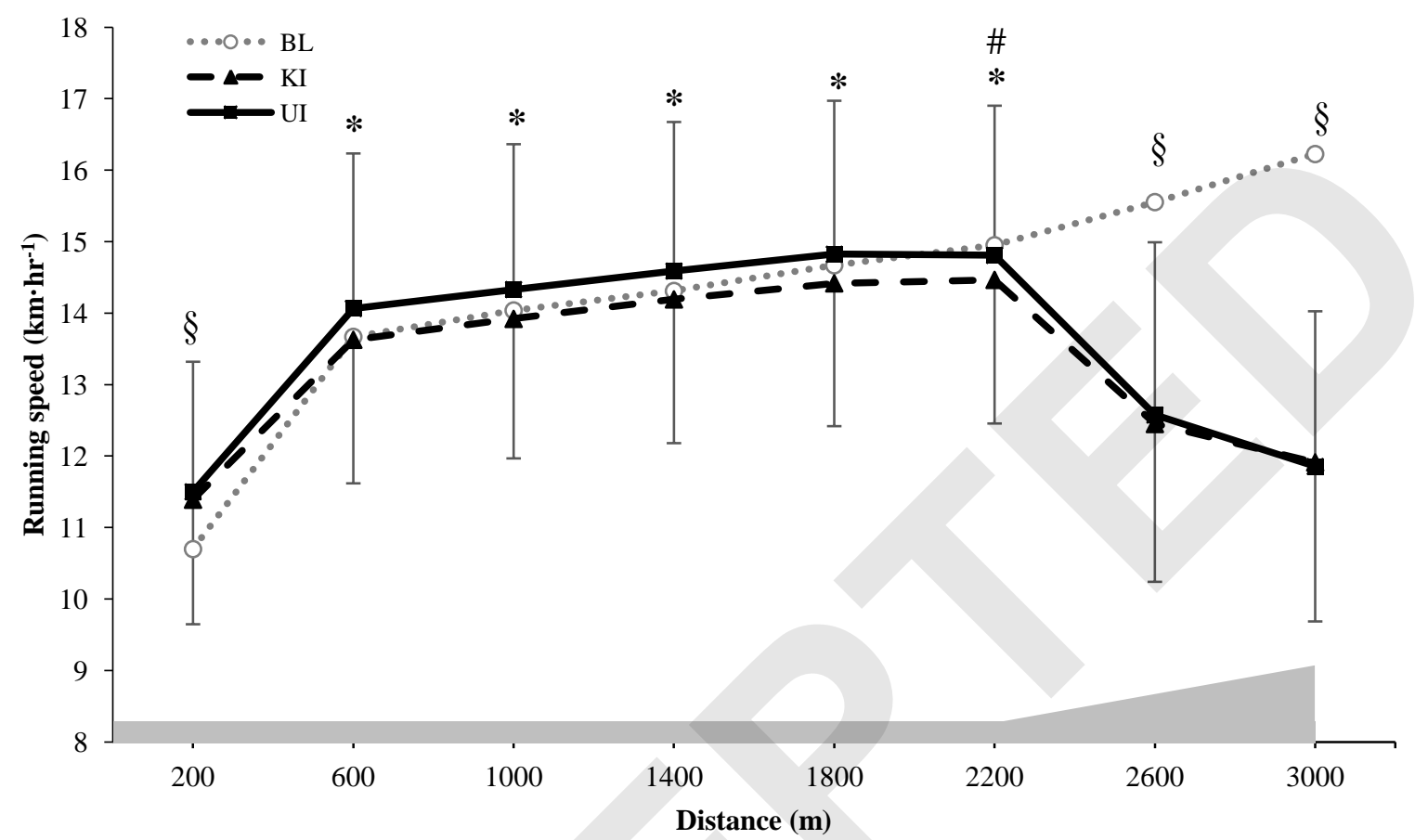

BL: Baseline time-trial; KI: Known incline time-trial; UI: Unknown incline time-trial. Symbols denote: * KI significantly different from UI. ${ }^{*}$ KI significantly different from BL. ${ }^{\S} \mathrm{KI}$ and UI both significantly different from BL.

Absolute running speed was faster at $\mathbf{2 0 0} \mathbf{~ m}$ during $\mathrm{KI}\left(\mathrm{MD}=0.69 \mathrm{~km} \cdot \mathrm{hr}^{-1}\right.$; $95 \% \mathrm{CI}, 0.09,1.30$; $P=.022, d=0.40)$ and UI $\left(\mathrm{MD}=0.80 \mathrm{~km} \cdot \mathrm{hr}^{-1} ; 95 \% \mathrm{CI}, 0.24,1.37 ; P=.004, d=0.46\right)$ than BL. Absolute running speed was slower during KI than UI at $600 \mathbf{~ m}\left(\mathrm{MD}=-0.44 \mathrm{~km} \cdot \mathrm{hr}^{-1} ; 95 \% \mathrm{CI},-\right.$ 0.84, -0.04; $P=.029, d=-0.20) 1000 \mathrm{~m}\left(\mathrm{MD}=-0.41 \mathrm{~km} \cdot \mathrm{hr}^{-1} ; 95 \% \mathrm{CI},-0.73,-0.09 ; P=.009, d\right.$ $=-0.20) 1400 \mathrm{~m}\left(\mathrm{MD}=-0.40 \mathrm{~km} \cdot \mathrm{hr}^{-1} ; 95 \% \mathrm{CI},-0.68,-0.11 ; P=.005, d=-0.19\right), 1800 \mathrm{~m}(\mathrm{MD}=$ $\left.-0.41 \mathrm{~km} \cdot \mathrm{hr}^{-1} ; 95 \% \mathrm{CI},-0.70,-0.11 ; P=.005, d=-0.19\right)$, and $2200 \mathrm{~m}\left(\mathrm{MD}=-0.34 \mathrm{~km} \cdot \mathrm{hr}^{-1} ; 95 \%\right.$ CI, $-0.64,-0.05 ; P=.020, d=-0.16)$

Absolute running speed was slower during $\mathrm{KI}$ than BL (MD $=-0.49 \mathrm{~km} \cdot \mathrm{hr}^{-1} ; 95 \% \mathrm{CI},-0.87$, $0.10 ; P=.011, d=-0.22)$ at $\mathbf{2 2 0 0} \mathbf{~ m}$ 
Absolute running speed was slower at $\mathbf{2 6 0 0} \mathbf{m}$ during $\mathrm{KI}\left(\mathrm{MD}=-3.11 \mathrm{~km} \cdot \mathrm{hr}^{-1}\right.$; 95\% CI, -3.53, 2.68; $P<.001, d=-1.35)$ and UI $\left(\mathrm{MD}=-2.98 \mathrm{~km} \cdot \mathrm{hr}^{-1} ; 95 \% \mathrm{CI},-3.45,-2.51 ; P<.001, d=-1.30\right)$ than BL.

Absolute running speed was slower at $\mathbf{3 0 0 0} \mathbf{m}$ during $\mathrm{KI}\left(\mathrm{MD}=-4.32 \mathrm{~km} \cdot \mathrm{hr}^{-1}\right.$; 95\% CI, -4.85, $3.78 ; P<.001, d=-1.66)$ and UI (MD $\left.=-4.37 \mathrm{~km} \cdot \mathrm{hr}^{-1} ; 95 \% \mathrm{CI},-4.92,-3.82 ; P<.001, d=-1.68\right)$ than BL

Copyright (@ 2018 by the American College of Sports Medicine. Unauthorized reproduction of this article is prohibited. 
Figure SDC1c. Analysis of perceived effort data at each distance interval

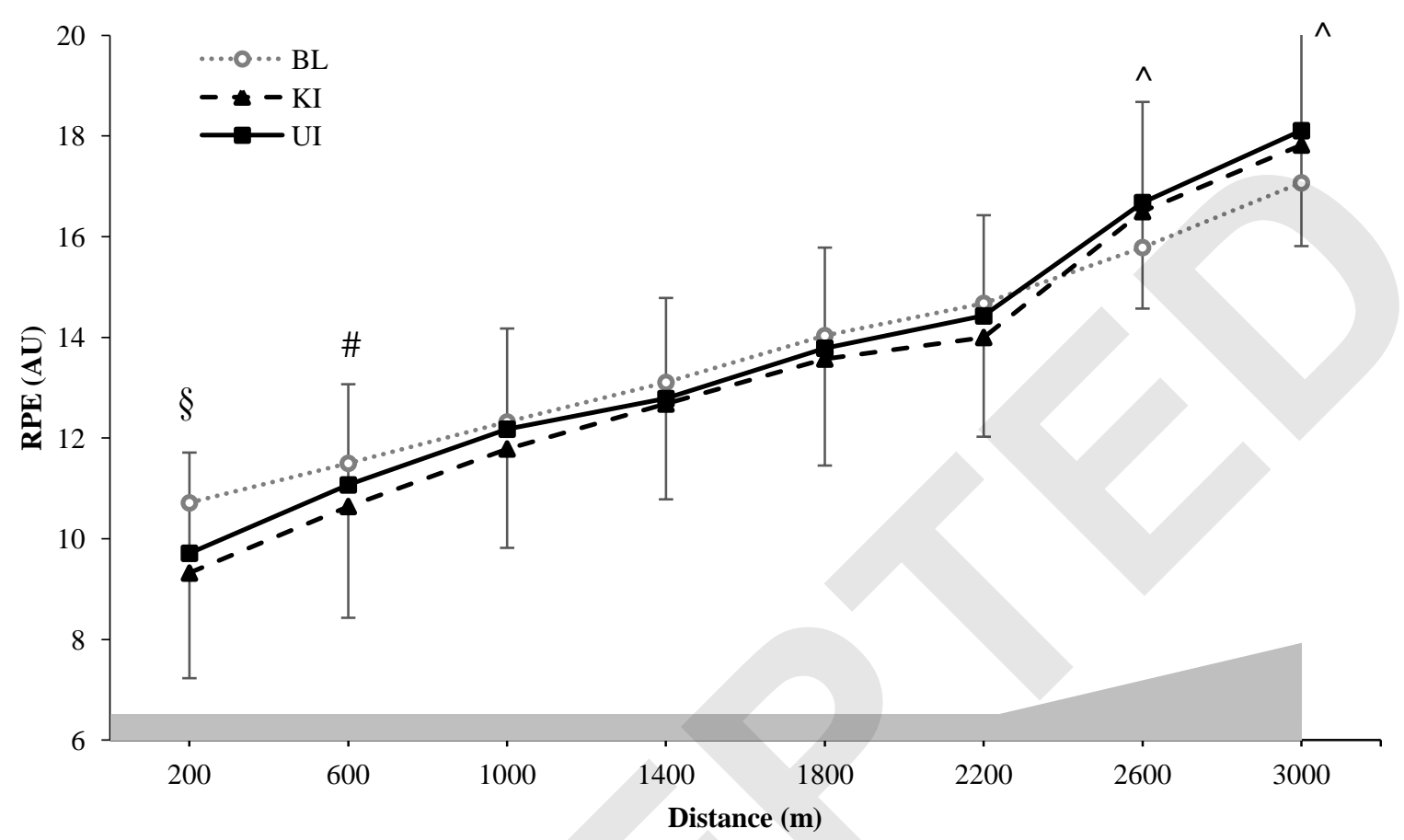

BL: Baseline time-trial; KI: Known incline time-trial; UI: Unknown incline time-trial.

Symbols denote: ${ }^{\S} \mathrm{KI}$ and UI both significantly different from BL. ${ }^{\text {K }} \mathrm{KI}$ significantly different from BL. ^ UI significantly different from BL.

Rating of perceived effort was lower at $\mathbf{2 0 0}$ m during KI (MD = -1.39; 95\% CI, -2.18, $-0.60 ; P<$ $.001, d=-0.69)$ and UI (MD $=-1.00 ; 95 \% \mathrm{CI},-1.76,-0.24 ; P=.007, d=-0.50)$ than $\mathrm{BL}$

Rating of perceived effort was lower during KI than BL at 600 m $(\mathrm{MD}=-0.86 ; 95 \% \mathrm{CI},-1.55$, $0.17 ; P=.011, d=-0.40)$.

Rating of perceived effort was higher during UI than BL at 2600 m $(\mathrm{MD}=0.89 ; 95 \%$ CI, 0.17, $1.61 ; P=.012, d=0.49)$.

Rating of perceived effort was higher during UI than BL at 3000 m $(\mathrm{MD}=1.04 ; 95 \% \mathrm{CI}, 0.11$, $1.97 ; P=.026, d=0.60)$. 
Figure SDC1d. Analysis of affective valence data at each distance interval

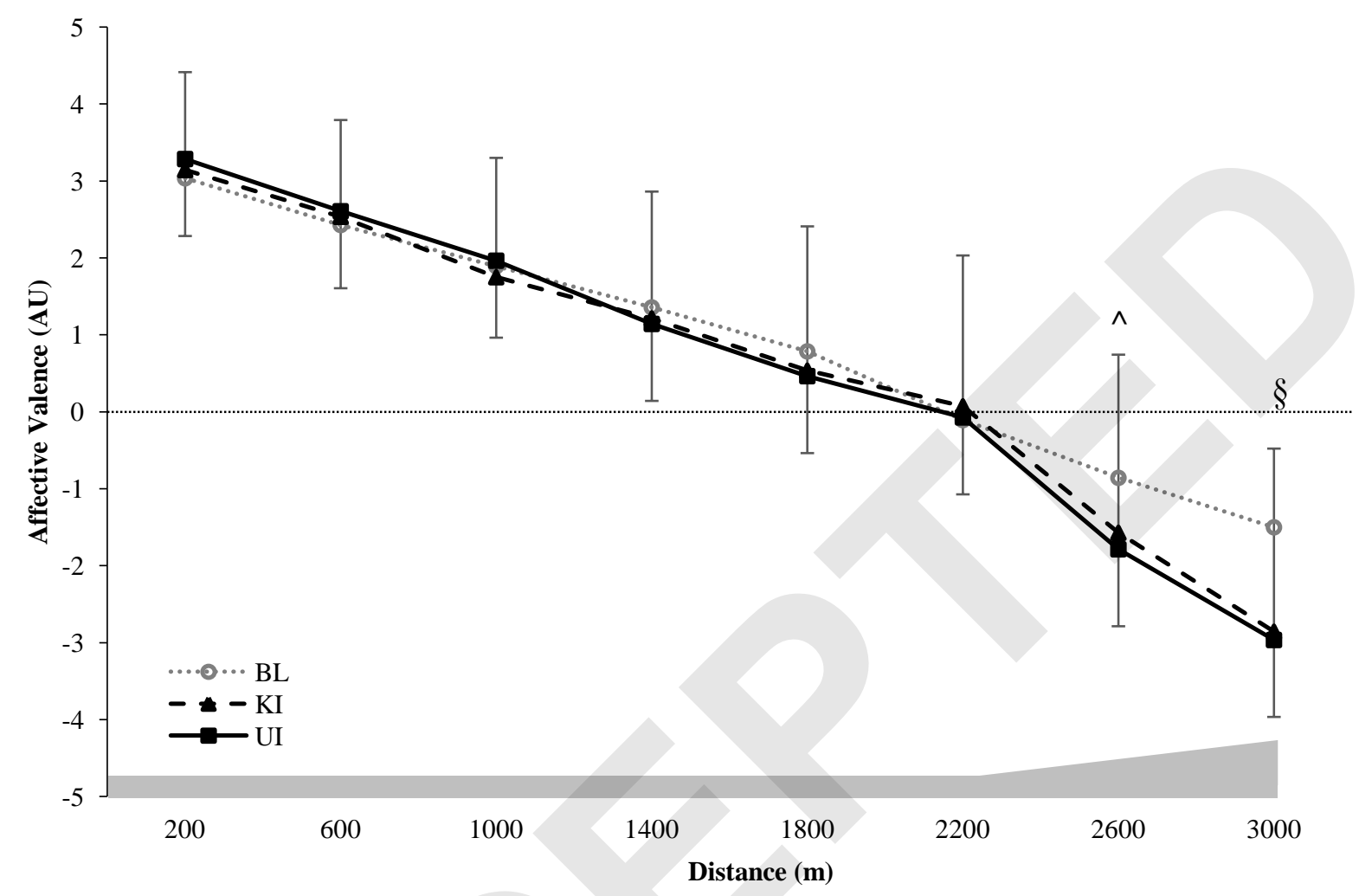

BL: Baseline time-trial; KI: Known incline time-trial; UI: Unknown incline time-trial. Symbols denote: ^ UI significantly different from BL. ${ }^{\S} \mathrm{KI}$ and UI both significantly different from BL.

Affective valence was more negative during UI than BL at $2600 \mathbf{~ m}(\mathrm{MD}=-0.93 ; 95 \% \mathrm{CI},-1.69$, $-0.17 ; P=.013, d=-0.40)$.

Affective valence was more negative at $\mathbf{3 0 0 0} \mathbf{~ m}$ during $\mathrm{KI}(\mathrm{MD}=-1.63 ; 95 \% \mathrm{CI},-2.20,-0.52 ; P$ $=.001, d=-0.53)$ and $\mathrm{UI}(\mathrm{MD}=-1.46 ; 95 \% \mathrm{CI},-2.27,-0.66 ; P<.001, d=-0.57)$ than $\mathrm{BL}$ 
Figure SDC1e. Analysis of heart rate data at each distance interval

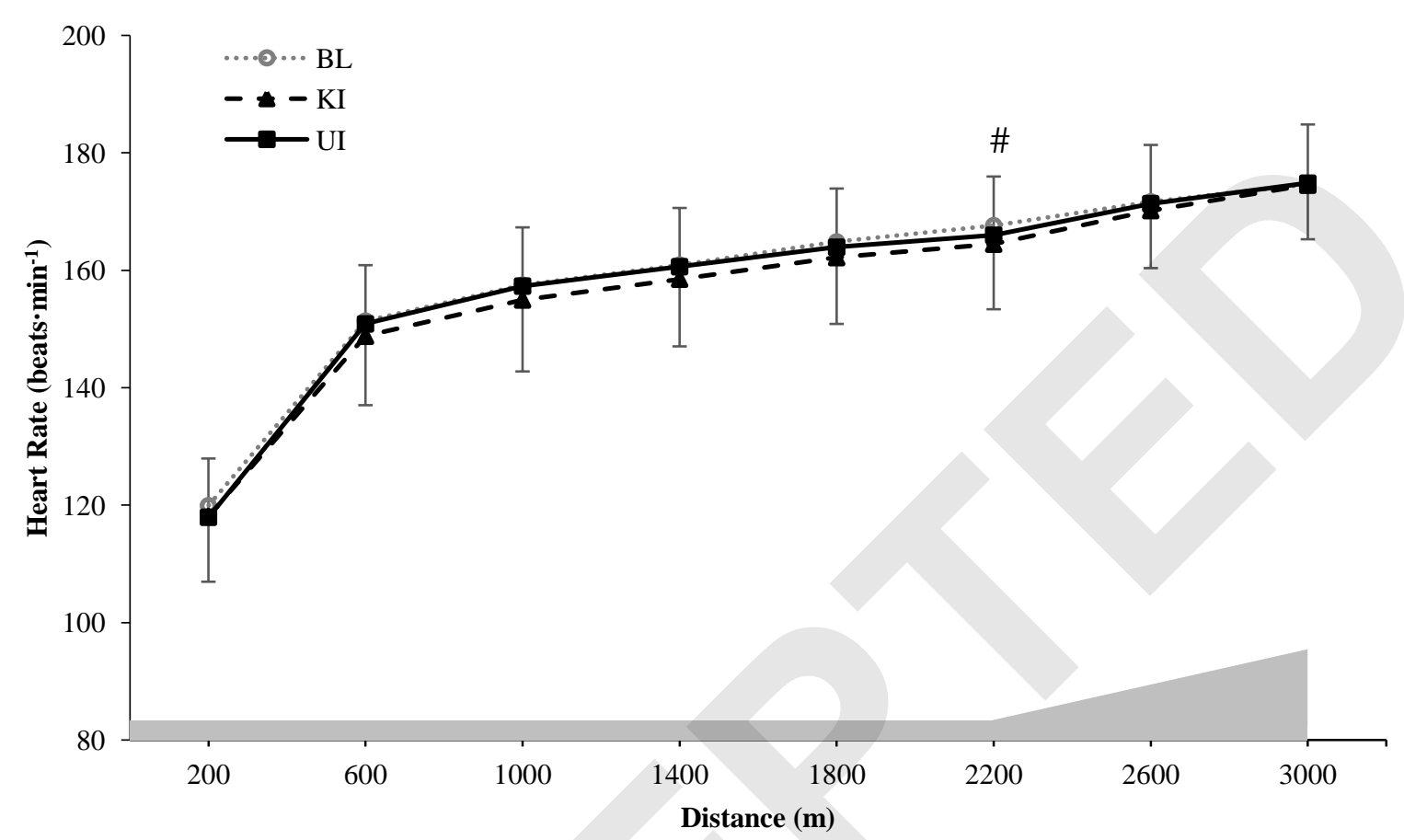

BL: Baseline time-trial; KI: Known incline time-trial; UI: Unknown incline time-trial. Symbols denote: ${ }^{\#}$ KI significantly different from BL.

Heart rate was lower during KI than $\mathrm{BL}$ at $\mathbf{2 2 0 0} \mathbf{~ m}\left(\mathrm{MD}=-3.16 \mathrm{~b} \cdot \mathrm{min}^{-1} ; 95 \% \mathrm{CI}=-6.22,-0.11\right.$; $P=.041, d=-0.30)$ 
Figure SDC1f. Analysis of blood lactate data

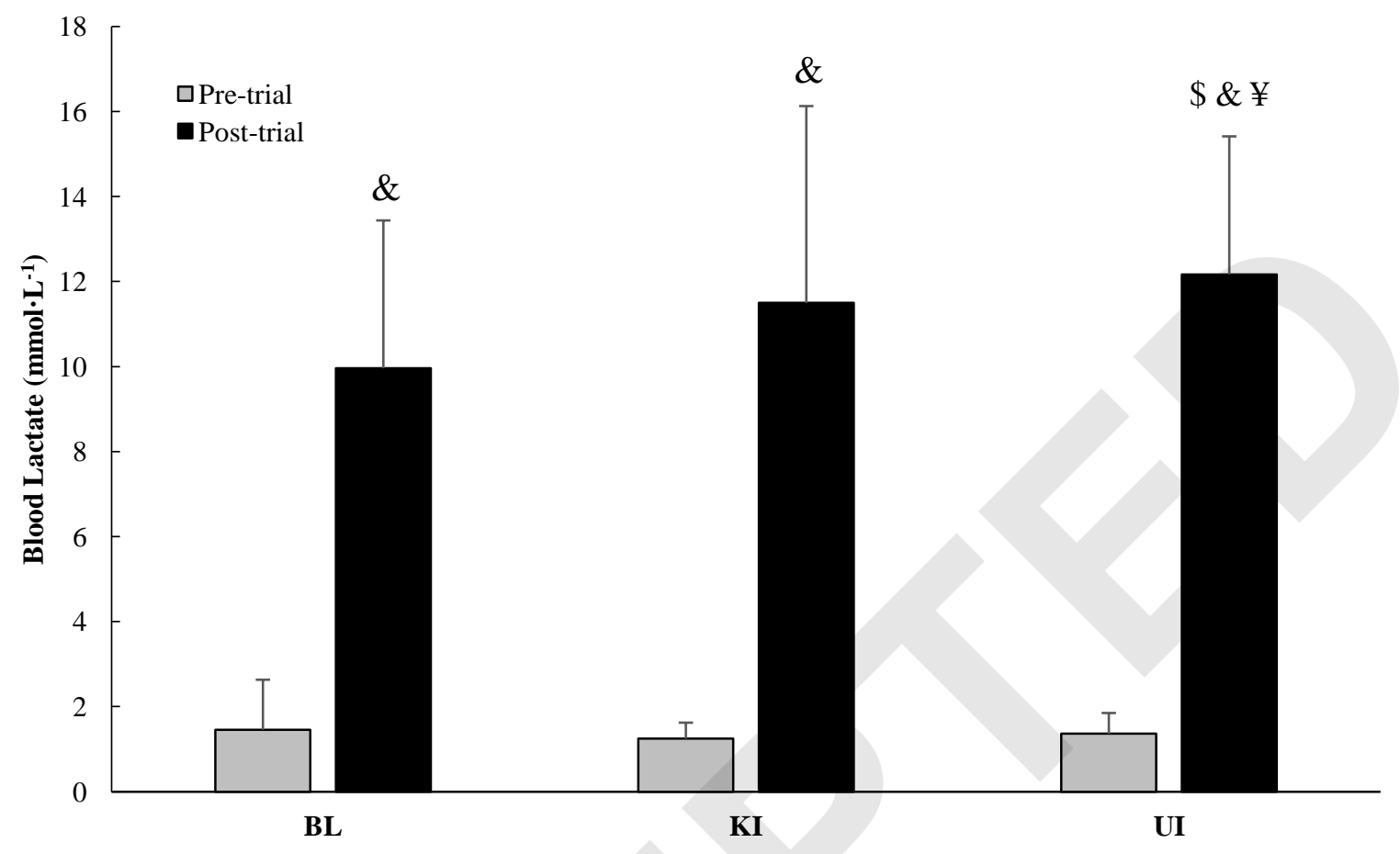

BL: Baseline time-trial; KI: Known incline time-trial; UI: Unknown incline time-trial. Symbols denote: ${ }^{\$}$ Condition $\mathrm{x}$ time interaction effect. ${ }^{¥}$ Main effect for condition. ${ }^{\&}$ Main effect for time.

There was a significant interaction between condition and measurement time, $F_{2,54}=8.50, P=$ $.001, \eta_{p}{ }^{2}=0.24$.

A main effect for condition, $F_{2,54}=7.14, P=.002, \eta_{p}{ }^{2}=0.21$, revealed that blood lactate was higher in UI than $\mathrm{BL}\left(\mathrm{MD}=1.06 \mathrm{mmol} \cdot \mathrm{L}^{-1} ; 95 \% \mathrm{CI}, 0.51,1.60 ; P<.001\right)$

A main effect for time, $F_{1,27}=200.94, P<.001, \eta_{p}{ }^{2}=0.89$, revealed that blood lactate increased from pre-trial to post-trial for all time-trials $\left(\mathrm{MD}=9.85 \mathrm{mmol} \cdot \mathrm{L}^{-1} ; 95 \% \mathrm{CI}, 8.49,11.21 ; P<\right.$ $.001)$. 
Table SDC2a. Correlations between the relative running speed and pre-trial psychological states during the known incline (KI) time-trial

\begin{tabular}{ccccccccccc}
\hline & Motivation & $\begin{array}{c}\text { Total Mood } \\
\text { Disturbance }\end{array}$ & Tension & Depression & Anger & Fatigue & Confusion & Vigor \\
\hline & & $.458^{*}$ & -.286 & .198 & -.251 & -.096 & -.085 & .114 \\
Relative speed at $1000 \mathrm{~m}$ & {$[.175, .687]$} & {$[-.551, .052]$} & {$[-.286, .538]$} & {$[-.533, .039]$} & {$[-.415, .117]$} & {$[-.436, .275]$} & {$[-.425, .476]$} & {$[.153, .611]$} \\
& $.422^{*}$ & -.278 & .131 & -.371 & -.150 & -.042 & -.011 & .360 \\
Relative speed at $2000 \mathrm{~m}$ & {$[.131, .699]$} & {$[-.536, .052]$} & {$[-.257, .551]$} & {$[-.634,-.117]$} & {$[-.302,-.049]$} & {$[-.331, .304]$} & {$[-.261, .180]$} & {$[.101, .571]$} \\
&.- .196 & .096 & .070 & .076 & .072 & .184 & -.037 & .015 \\
Relative speed at 3000 $\mathrm{m}$ & {$[-.512, .192]$} & {$[-.236, .399]$} & {$[-.294, .470]$} & {$[-.274, .435]$} & {$[-.311, .242]$} & {$[-.184, .443]$} & {$[-.306, .273]$} & {$[-.309, .340]$} \\
\hline
\end{tabular}

$* *$ Correlation is significant at the 0.01 level (2-tailed); *Correlation is significant at the 0.05 level (2-tailed)

Bias corrected and accelerated bootstrap $95 \%$ confidence intervals are reported in square brackets. Relative speed = change in speed expressed relative to BL at distance interval

\section{Analysis:}

Relative running speed at $\mathbf{1 0 0 0} \mathbf{~ m}$ during KI was positively correlated with pre-trial potential motivation, $r=.458,[.175, .687], p=.014$

Relative running speed at $\mathbf{1 0 0 0} \mathbf{~ m}$ during KI was positively correlated with pre-trial vigor, $r=.423,[.153, .611], p=.025$

Relative running speed at $\mathbf{2 0 0 0} \mathbf{~ m}$ during KI was positively correlated with pre-trial potential motivation, $r=.422$, [.131, .699], $p=.025$ 
Table SDC2b. Correlations between the relative running speed, perceived effort, affective valence and attentional focus frequency ratings at $1000 \mathrm{~m}$ during the known incline (KI) time-trial

\begin{tabular}{|c|c|c|c|c|c|c|}
\hline & 1 & 2 & 3 & 4 & 5 & 6 \\
\hline 1. Relative speed & 1 & & & & & \\
\hline 2. Perceived effort & $\begin{array}{c}.075 \\
{[-.279, .442]}\end{array}$ & 1 & & & & \\
\hline 3. Affective Valence & $\begin{array}{c}-.152 \\
{[-.567, .344]}\end{array}$ & $\begin{array}{c}-.572^{* *} \\
{[-.784,-.236]}\end{array}$ & 1 & & & \\
\hline 4. Active Self-Regulation & $\begin{array}{c}-.063 \\
{[-.451, .316]}\end{array}$ & $\begin{array}{c}.221 \\
{[-.214, .672]}\end{array}$ & $\begin{array}{c}-.040 \\
{[-.389, .295]}\end{array}$ & & & \\
\hline 5. Internal Sensory Monitoring & $\begin{array}{c}.214 \\
{[-.203, .516]}\end{array}$ & $\begin{array}{c}.136 \\
{[-.210, .595]}\end{array}$ & $\begin{array}{c}-.365 \\
{[-.686, .019]}\end{array}$ & $\begin{array}{c}.548^{* *} \\
{[.066, .891]}\end{array}$ & 1 & \\
\hline 6. Outward Monitoring & $\begin{array}{c}.171 \\
{[-.170, .496]}\end{array}$ & $\begin{array}{c}.300 \\
{[-.162, .686]}\end{array}$ & $\begin{array}{c}-.302 \\
{[-.601, .059]}\end{array}$ & $\begin{array}{c}.383^{*} \\
{[.034, .747]}\end{array}$ & $\begin{array}{c}.609^{* *} \\
{[.273, .851]}\end{array}$ & 1 \\
\hline
\end{tabular}

** Correlation is significant at the 0.01 level (2-tailed); *Correlation is significant at the 0.05 level (2-tailed)

Bias corrected and accelerated bootstrap 95\% confidence intervals are reported in square brackets. Relative speed $=$ change in speed expressed relative to BL at distance interval

\section{Analysis:}

Perceived effort at $\mathbf{1 0 0 0} \mathbf{~ m}$ during KI was inversely correlated with affective valence, $r=-.572,[-.784,-.236], p=.001$

Internal sensory monitoring at $\mathbf{1 0 0 0} \mathbf{~ m}$ during KI was positively correlated with active self-regulation, $r=.548,[.066, .891], p=.003$

Internal sensory monitoring at $\mathbf{1 0 0 0} \mathbf{~ m}$ during KI was positively correlated with outward monitoring, $r=.609,[.273, .851], p=.001$

Outward monitoring at $\mathbf{1 0 0 0} \mathbf{~ m}$ during KI was positively correlated with active self-regulation, $r=.383,[.034, .747], p=.044$ 
Table SDC2c. Correlations between the relative running speed, perceived effort, affective valence and attentional focus frequency ratings at $2000 \mathrm{~m}$ during the known incline (KI) time-trial

\begin{tabular}{|c|c|c|c|c|c|c|}
\hline & 1 & 2 & 3 & 4 & 5 & 6 \\
\hline 1. Relative speed & 1 & & & & & \\
\hline 2. Perceived effort & $\begin{array}{c}.382^{*} \\
{[-.041, .643]}\end{array}$ & 1 & & & & \\
\hline 3. Affective Valence & $\begin{array}{c}-.389 * \\
{[-.692, .089]}\end{array}$ & $\begin{array}{c}-.743 * * \\
{[-.900,-.459]}\end{array}$ & 1 & & & \\
\hline 4. Active Self-Regulation & $\begin{array}{c}-.050 \\
{[-.417, .276]}\end{array}$ & $\begin{array}{c}.201 \\
{[-.162, .515]}\end{array}$ & $\begin{array}{c}-.107 \\
{[-.415, .219]}\end{array}$ & & & \\
\hline 5. Internal Sensory Monitoring & $\begin{array}{c}.410^{*} \\
{[.031, .654]}\end{array}$ & $\begin{array}{c}.401 * \\
{[.064, .680]}\end{array}$ & $\begin{array}{c}-.373 \\
{[-.607,-.055]}\end{array}$ & $\begin{array}{c}.436^{*} \\
{[-.144, .901]}\end{array}$ & 1 & \\
\hline 6. Outward Monitoring & $\begin{array}{c}.316 \\
{[-.075, .570]}\end{array}$ & $\begin{array}{c}.376^{*} \\
{[-.070, .685]}\end{array}$ & $\begin{array}{c}-.321 \\
{[-.680, .125]}\end{array}$ & $\begin{array}{c}.175 \\
{[-.238, .607]}\end{array}$ & $\begin{array}{c}.582 * * \\
{[.246, .833]}\end{array}$ & 1 \\
\hline
\end{tabular}

**Correlation is significant at the 0.01 level (2-tailed); *Correlation is significant at the 0.05 level (2-tailed)

Bias corrected and accelerated bootstrap 95\% confidence intervals are reported in square brackets. Relative speed $=$ change in speed expressed relative to BL at distance interval

\section{Analysis:}

Relative running speed at $\mathbf{2 0 0 0} \mathbf{~ m}$ during KI was positively correlated with perceived effort, $r=.382,[-.041, .643], p=.045$

Relative running speed at $\mathbf{2 0 0 0} \mathbf{~ m}$ during KI was negatively correlated with affective valence, $r=-.389,[-.692, .089], p=.041$

Relative running speed at $\mathbf{2 0 0 0} \mathbf{~ m}$ during KI was positively correlated with internal sensory monitoring, $r=.410,[.031, .654], p=.030$

Perceived effort at $\mathbf{2 0 0 0} \mathbf{~ m}$ during KI was inversely correlated with affective valence, $r=-.743,[-.900,-.459], p<.001$

Perceived effort at $\mathbf{2 0 0 0} \mathbf{~ m}$ during KI was positively correlated with internal sensory monitoring, $r=.401,[.064, .680], p=.034$

Perceived effort at $\mathbf{2 0 0 0} \mathbf{~ m}$ during KI was positively correlated with outward monitoring, $r=.376,[-.070, .685], p=.048$

Internal sensory monitoring at $\mathbf{2 0 0 0} \mathbf{~ m}$ during KI was positively correlated with active self-regulation, $r=.436,[-.144, .901], p=.020$

Internal sensory monitoring at $\mathbf{2 0 0 0} \mathbf{~ m}$ during KI was positively correlated with outward monitoring, $r=.582,[.246, .833], p=.001$ 
Table SDC2d. Correlations between the relative running speed, perceived effort, affective valence and attentional focus frequency ratings at $3000 \mathrm{~m}$ during the known incline (KI) time-trial

\begin{tabular}{|c|c|c|c|c|c|c|}
\hline & 1 & 2 & 3 & 4 & 5 & 6 \\
\hline 1. Relative speed & 1 & & & & & \\
\hline 2. Perceived effort & $\begin{array}{c}.098 \\
{[-.250, .425]}\end{array}$ & 1 & & & & \\
\hline 3. Affective Valence & $\begin{array}{c}-.149 \\
{[-.461, .137]}\end{array}$ & $\begin{array}{c}-.763 * * \\
{[-.910,-.604]}\end{array}$ & 1 & & & \\
\hline 4. Active Self-Regulation & $\begin{array}{c}-.368 \\
{[-.613,-.108]}\end{array}$ & $\begin{array}{c}.224 \\
{[-.134, .584]}\end{array}$ & $\begin{array}{c}-.096 \\
{[-.407, .194]}\end{array}$ & & & \\
\hline 5. Internal Sensory Monitoring & $\begin{array}{c}-.163 \\
{[-.516, .258]}\end{array}$ & $\begin{array}{c}.452^{*} \\
{[.115, .742]}\end{array}$ & $\begin{array}{c}-.405^{*} \\
{[-.658,-.162]}\end{array}$ & $\begin{array}{c}.247 \\
{[-.234, .895]}\end{array}$ & 1 & \\
\hline 6. Outward Monitoring & $\begin{array}{c}.113 \\
{[-.264, .514]}\end{array}$ & $\begin{array}{c}.467 * \\
{[.167, .729]}\end{array}$ & $\begin{array}{c}-.498 * * \\
{[-.767,-.221]}\end{array}$ & $\begin{array}{c}-.039 \\
{[-.385, .384]}\end{array}$ & $\begin{array}{c}.480 * * \\
{[.143, .764]}\end{array}$ & 1 \\
\hline
\end{tabular}

*** Correlation is significant at the 0.01 level (2-tailed); *Correlation is significant at the 0.05 level (2-tailed)

Bias corrected and accelerated bootstrap 95\% confidence intervals are reported in square brackets. Relative speed $=$ change in speed expressed relative to BL at distance interval

\section{Analysis:}

Perceived effort at $\mathbf{3 0 0 0} \mathbf{~ m}$ during KI was inversely correlated with affective valence, $r=-.763,[-.910,-.604], p<.001$

Perceived effort at $\mathbf{3 0 0 0} \mathbf{~ m}$ during KI was positively correlated with internal sensory monitoring, $r=.452,[.115, .742], p=.016$

Perceived effort at $\mathbf{3 0 0 0} \mathbf{~ m}$ during KI was positively correlated with outward monitoring, $r=.467,[.167, .729], p=.012$

Affective valence at $\mathbf{3 0 0 0} \mathbf{~ m}$ during KI was inversely correlated with internal sensory monitoring, $r=-.405,[-.658,-.162], p=.032$

Affective valence at $\mathbf{3 0 0 0} \mathbf{~ m}$ during KI was inversely correlated with outward monitoring, $r=-.498$, [-.767, -.221], $p=.007$

Internal sensory monitoring at $\mathbf{3 0 0 0} \mathbf{~ m}$ during KI was positively correlated with outward monitoring, $r=.480,[.143, .764], p=.010$ 
Table SDC2e. Correlations between the relative running speed and pre-trial psychological states during the unknown incline (UI) time-trial

\begin{tabular}{|c|c|c|c|c|c|c|c|c|}
\hline & $\begin{array}{c}\text { Potential } \\
\text { Motivation }\end{array}$ & $\begin{array}{l}\text { Total Mood } \\
\text { Disturbance }\end{array}$ & Tension & Depression $^{\mathrm{a}}$ & Anger ${ }^{a}$ & Vigor & Fatigue & Confusion \\
\hline Relative speed at $1000 \mathrm{~m}$ & $\begin{array}{c}.150 \\
{[-.168, .506]}\end{array}$ & $\begin{array}{c}.154 \\
{[-.381, .530]}\end{array}$ & $\begin{array}{c}.060 \\
{[-.408, .369]}\end{array}$ & - & - & $\begin{array}{c}-.261 \\
{[-.642, .313]}\end{array}$ & $\begin{array}{c}-.053 \\
{[-.500, .379]}\end{array}$ & $\begin{array}{c}-.193 \\
{[-.586, .310]}\end{array}$ \\
\hline Relative speed at $2000 \mathrm{~m}$ & $\begin{array}{c}.069 \\
{[-.283, .313]}\end{array}$ & $\begin{array}{c}.216 \\
{[-.178, .598]}\end{array}$ & $\begin{array}{c}.059 \\
{[-.257, .440]}\end{array}$ & - & - & $\begin{array}{c}-.220 \\
{[-.531, .120]}\end{array}$ & $\begin{array}{c}.148 \\
{[-.250, .491]}\end{array}$ & $\begin{array}{c}-.265 \\
{[-.537, .026]}\end{array}$ \\
\hline Relative speed at $3000 \mathrm{~m}$ & $\begin{array}{c}.026 \\
{[-.309, .368]}\end{array}$ & $\begin{array}{c}.036 \\
{[-.323, .393]}\end{array}$ & $\begin{array}{c}-.218 \\
{[-.536, .193]}\end{array}$ & - & & $\begin{array}{c}-.064 \\
{[-.389, .244]}\end{array}$ & $\begin{array}{c}.131 \\
{[-.169, .406]}\end{array}$ & $\begin{array}{c}.059 \\
{[-.229, .276]}\end{array}$ \\
\hline
\end{tabular}

$* *$ Correlation is significant at the 0.01 level (2-tailed); *Correlation is significant at the 0.05 level (2-tailed)

Bias corrected and accelerated bootstrap 95\% confidence intervals are reported in square brackets. Relative speed = change in speed expressed relative to BL at distance interval ${ }^{a}$ Both pre-trial depression and anger mood state scores were zero for UI time-trial

\section{Analysis:}

No pre-trial psychological variables were associated with the relative change in running speed at any distance interval during UI 
Table SDC2f. Correlations between the relative running speed, perceived effort, affective valence and attentional focus frequency ratings at $1000 \mathrm{~m}$ during the unknown incline (UI) time-trial

\begin{tabular}{|c|c|c|c|c|c|c|}
\hline & 1 & 2 & 3 & 4 & 5 & 6 \\
\hline 1. Relative speed & 1 & & & & & \\
\hline 2. Perceived effort & $\begin{array}{c}-.089 \\
{[-.393, .247]}\end{array}$ & 1 & & & & \\
\hline 3. Affective Valence & $\begin{array}{c}-.060 \\
{[-.387, .258]}\end{array}$ & $\begin{array}{c}-.559 * * \\
{[-.813,-.147]}\end{array}$ & 1 & & & \\
\hline 4. Active Self-Regulation & $\begin{array}{c}-.318 \\
{[-.581,-.004]}\end{array}$ & $\begin{array}{c}.268 \\
{[-.178, .627]}\end{array}$ & $\begin{array}{c}.120 \\
{[-.326, .506]}\end{array}$ & & & \\
\hline 5. Internal Sensory Monitoring & $\begin{array}{c}-.324 \\
{[-.561,-.043]}\end{array}$ & $\begin{array}{c}.329 \\
{[.046, .614]}\end{array}$ & {$[-.551,-.021]$} & $\begin{array}{c}.305 \\
{[-.134, .756]}\end{array}$ & 1 & \\
\hline 6. Outward Monitoring & $\begin{array}{c}-.140 \\
{[-.473, .234]}\end{array}$ & $\begin{array}{c}.064 \\
{[-.379, .456]}\end{array}$ & $\begin{array}{c}-.215 \\
{[-.546, .125]}\end{array}$ & $\begin{array}{c}.200 \\
{[-.176, .626]}\end{array}$ & $\begin{array}{c}.349 \\
{[.032, .645]}\end{array}$ & 1 \\
\hline
\end{tabular}

**Correlation is significant at the 0.01 level (2-tailed); *Correlation is significant at the 0.05 level (2-tailed)

Bias corrected and accelerated bootstrap $95 \%$ confidence intervals are reported in square brackets. Relative speed $=$ change in speed expressed relative to BL at distance interval

\section{Analysis:}

Perceived effort at $\mathbf{1 0 0 0} \mathbf{~ m}$ during UI was inversely correlated with affective valence, $r=-.559,[-.813,-.147], p=.002$ 
Table SDC2g. Correlations between the relative running speed, perceived effort, affective valence and attentional focus frequency ratings at $2000 \mathrm{~m}$ during the unknown incline (UI) time-trial

\begin{tabular}{|c|c|c|c|c|c|c|}
\hline & 1 & 2 & 3 & 4 & 5 & 6 \\
\hline 1. Relative speed & 1 & & & & & \\
\hline 2. Perceived effort & $\begin{array}{c}.127 \\
{[-.241, .414]}\end{array}$ & 1 & & & & \\
\hline 3. Affective Valence & $\begin{array}{c}-.130 \\
{[-.536, .378]}\end{array}$ & $\begin{array}{c}-.584 * * \\
{[-.805, .293]}\end{array}$ & 1 & & & \\
\hline 4. Active Self-Regulation & $\begin{array}{c}-.274 \\
{[-.574, .006]}\end{array}$ & $\begin{array}{c}.216 \\
{[-.261, .754]}\end{array}$ & $\begin{array}{c}-.080 \\
{[-.411, .310]}\end{array}$ & & & \\
\hline 5. Internal Sensory Monitoring & $\begin{array}{c}.121 \\
{[-.188, .365]}\end{array}$ & $\begin{array}{c}.374 * \\
{[-.260, .837]}\end{array}$ & $\begin{array}{c}-.211 \\
{[-.509, .117]}\end{array}$ & $\begin{array}{c}.017 \\
{[-.497, .648]}\end{array}$ & 1 & \\
\hline 6. Outward Monitoring & $\begin{array}{c}.001 \\
{[-.333, .314]}\end{array}$ & $\begin{array}{c}.234 \\
{[-.281, .648]}\end{array}$ & $\begin{array}{c}-.143 \\
{[-.510, .256]}\end{array}$ & $\begin{array}{c}-.055 \\
{[-.459, .392]}\end{array}$ & $\begin{array}{c}.701 * * \\
{[.446, .856]}\end{array}$ & 1 \\
\hline
\end{tabular}

**Correlation is significant at the 0.01 level (2-tailed); *Correlation is significant at the 0.05 level (2-tailed)

Bias corrected and accelerated bootstrap 95\% confidence intervals are reported in square brackets. Relative speed $=$ change in speed expressed relative to BL at distance interval

\section{Analysis:}

Perceived effort at $\mathbf{2 0 0 0} \mathbf{~ m}$ during UI was inversely correlated with affective valence, $r=-.584,[-.805, .293], p=.001$

Perceived effort at $\mathbf{2 0 0 0} \mathbf{~ m}$ during UI was positively correlated with internal sensory monitoring, $r=.374,[-.260, .837], p=.050$

Internal sensory monitoring at $\mathbf{2 0 0 0} \mathbf{~ m}$ during UI was positively correlated with outward monitoring, $r=.701,[.446, .856], p<.001$ 
Table SDC2h. Correlations between the relative running speed, perceived effort, affective valence and attentional focus frequency ratings at $3000 \mathrm{~m}$ during the unknown incline (UI) time-trial

\begin{tabular}{|c|c|c|c|c|c|c|}
\hline & 1 & 2 & 3 & 4 & 5 & 6 \\
\hline 1. Relative speed & 1 & & & & & \\
\hline 2. Perceived effort & $\begin{array}{c}-.269 \\
{[-.468,-.078]}\end{array}$ & 1 & & & & \\
\hline 3. Affective Valence & $\begin{array}{c}.178 \\
{[-.085, .444]}\end{array}$ & $\begin{array}{c}-.744 * * \\
{[-.882,-.627]}\end{array}$ & 1 & & & \\
\hline 4. Active Self-Regulation & $\begin{array}{c}-.093 \\
{[-.398, .278]}\end{array}$ & $\begin{array}{c}.267 \\
{[-.129, .622]}\end{array}$ & $\begin{array}{c}-.043 \\
{[-.399, .284]}\end{array}$ & & & \\
\hline 5. Internal Sensory Monitoring & $\begin{array}{c}-.249 \\
{[-.531, .222]}\end{array}$ & $\begin{array}{c}.431^{*} \\
{[.044, .714]}\end{array}$ & $\begin{array}{c}-.165 \\
{[-.452, .101]}\end{array}$ & $\begin{array}{c}.578 * * \\
{[.108, .842}\end{array}$ & 1 & \\
\hline 6. Outward Monitoring & $\begin{array}{c}-.257 \\
{[-.561, .061]}\end{array}$ & $\begin{array}{c}.004 \\
{[-.356, .492]}\end{array}$ & $\begin{array}{c}-.088 \\
{[-.549, .292]}\end{array}$ & $\begin{array}{c}.150 \\
{[-.298, .621]}\end{array}$ & $\begin{array}{c}.381^{*} \\
{[-.167, .713]}\end{array}$ & 1 \\
\hline
\end{tabular}

**Correlation is significant at the 0.01 level (2-tailed); *Correlation is significant at the 0.05 level (2-tailed)

Bias corrected and accelerated bootstrap 95\% confidence intervals are reported in square brackets. Relative speed $=$ change in speed expressed relative to BL at distance interval

\section{Analysis:}

Perceived effort at $\mathbf{3 0 0 0} \mathbf{~ m}$ during UI was inversely correlated with affective valence, $r=-.744,[-.882,-.627], p<.001$

Perceived effort at $\mathbf{3 0 0 0} \mathbf{~ m}$ during UI was positively correlated with internal sensory monitoring, $r=.431,[.044, .714], p=.022$

Internal sensory monitoring at $\mathbf{3 0 0 0} \mathbf{~ m}$ during UI was positively correlated with active self-regulation, $r=.578,[.108, .842], p=.001$

Internal sensory monitoring at $\mathbf{3 0 0 0} \mathbf{~ m}$ during UI was positively correlated with outward monitoring, $r=.381,[-.167, .713], p=.046$ 
Table SDC3a. Active self-regulation category content at $\mathbf{1 0 0 0} \mathbf{~ m}$ for all time-trials. Figures represent percent of subjects reporting each focus.

\begin{tabular}{|c|c|c|c|c|c|c|c|c|c|c|c|c|}
\hline & Pacing & Relaxing & Chunking & Self-Talk & Technique & Cadence & Mindful & Objective & Imagery & Counting & Meditation & Other \\
\hline BL & 57.14 & 53.57 & 21.43 & 7.14 & 32.14 & 14.29 & 14.29 & 14.29 & 10.71 & 10.71 & 0.00 & 0.00 \\
\hline KI & 82.14 & 42.86 & 3.57 & 3.57 & 35.71 & 17.86 & 0.00 & 17.86 & 10.71 & 7.14 & 0.00 & 7.14 \\
\hline UI & 67.86 & 60.71 & 17.86 & 17.86 & 21.43 & 7.14 & 7.14 & 14.29 & 7.14 & 10.71 & 0.00 & 3.57 \\
\hline
\end{tabular}

Table SDC3b. Active self-regulation category content at $\mathbf{2 0 0 0} \mathbf{~ m}$ for all time-trials. Figures represent percent of subjects reporting each focus.

\begin{tabular}{|c|c|c|c|c|c|c|c|c|c|c|c|c|}
\hline & Pacing & Relaxing & Chunking & Self-Talk & Technique & Cadence & Mindful & Objective & Imagery & Counting & Meditation & Other \\
\hline BL & 64.29 & 60.71 & 28.57 & 14.29 & 28.57 & 7.14 & 14.29 & 10.71 & 14.29 & 10.71 & 3.57 & 3.57 \\
\hline KI & 85.71 & 53.57 & 21.43 & 17.86 & 21.43 & 21.43 & 7.14 & 14.29 & 3.57 & 7.14 & 0.00 & 3.57 \\
\hline UI & 67.86 & 50.00 & 25.00 & 28.57 & 28.57 & 10.71 & 14.29 & 21.43 & 14.29 & 3.57 & 0.00 & 3.57 \\
\hline
\end{tabular}

Table SDC3c. Active self-regulation category content at $\mathbf{3 0 0 0} \mathbf{m}$ for all time-trials. Figures represent percent of subjects reporting each focus.

\begin{tabular}{|c|c|c|c|c|c|c|c|c|c|c|c|c|}
\hline & Pacing & Relaxing & Chunking & Self-Talk & Technique & Cadence & Mindful & Objective & Imagery & Counting & Meditation & Other \\
\hline BL & 67.86 & 50.00 & 32.14 & 28.57 & 25.00 & 21.43 & 10.71 & 25.00 & 28.57 & 14.29 & 0.00 & 3.57 \\
\hline KI & 53.57 & 35.71 & 42.86 & 42.86 & 17.86 & 17.86 & 10.71 & 10.71 & 32.14 & 17.86 & 0.00 & 7.14 \\
\hline UI & 67.86 & 17.86 & 28.57 & 71.43 & 32.14 & 14.29 & 7.14 & 25.00 & 17.86 & 14.29 & 0.00 & 0.00 \\
\hline
\end{tabular}


Table SDC3d. Internal sensory monitoring category content at $\mathbf{1 0 0 0} \mathbf{~ m}$ for all time-trials. Figures represent percent of subjects reporting each focus.

\begin{tabular}{|c|c|c|c|c|c|c|c|c|c|c|c|}
\hline & Move/form & Exert pain & Muscle Sore. & Fatigue & Breathing & Temp & Thirst & Perspiration & Effort/Feel & Heart rate & Other \\
\hline BL & 42.86 & 0.00 & 14.29 & 0.00 & 60.71 & 7.14 & 3.57 & 3.57 & 25.00 & 10.71 & 0.00 \\
\hline KI & 32.14 & 0.00 & 14.29 & 10.71 & 60.71 & 17.86 & 7.14 & 17.86 & 14.29 & 3.57 & 7.14 \\
\hline UI & 35.71 & 0.00 & 3.57 & 17.86 & 60.71 & 7.14 & 3.57 & 10.71 & 25.00 & 7.14 & 0.00 \\
\hline
\end{tabular}

Table SDC3e. Internal sensory monitoring category content at $\mathbf{2 0 0 0} \mathbf{~ m}$ for all time-trials. Figures represent percent of subjects reporting each focus.

\begin{tabular}{|c|c|c|c|c|c|c|c|c|c|c|c|}
\hline & Move/form & Exert pain & Muscle Sore. & Fatigue & Breathing & Temp & Thirst & Perspiration & Effort/Feel & Heart rate & Other \\
\hline BL & 50.00 & 0.00 & 10.71 & 3.57 & 75.00 & 7.14 & 10.71 & 14.29 & 32.14 & 10.71 & 0.00 \\
\hline KI & 28.57 & 0.00 & 10.71 & 10.71 & 75.00 & 17.86 & 10.71 & 28.57 & 25.00 & 7.14 & 0.00 \\
\hline UI & 28.57 & 3.57 & 3.57 & 10.71 & 75.00 & 25.00 & 17.86 & 25.00 & 25.00 & 14.29 & 0.00 \\
\hline
\end{tabular}

Table SDC3f. Internal sensory monitoring category content at $\mathbf{3 0 0 0} \mathbf{~ m}$ for all time-trials. Figures represent percent of subjects reporting each focus.

\begin{tabular}{|c|c|c|c|c|c|c|c|c|c|c|c|}
\hline & Move/form & Exert pain & Muscle Sore. & Fatigue & Breathing & Temp & Thirst & Perspiration & Effort/Feel & Heart rate & Other \\
\hline BL & 28.57 & 7.14 & 10.71 & 17.86 & 67.86 & 14.29 & 14.29 & 21.43 & 50.00 & 10.71 & 7.14 \\
\hline KI & 28.57 & 17.86 & 3.57 & 39.29 & 78.57 & 10.71 & 10.71 & 28.57 & 57.14 & 10.71 & 0.00 \\
\hline UI & 21.43 & 17.86 & 7.14 & 28.57 & 78.57 & 14.29 & 3.57 & 28.57 & 71.43 & 7.14 & 0.00 \\
\hline
\end{tabular}


Table SDC3g. Outward monitoring category content at $\mathbf{1 0 0 0} \mathbf{~ m}$ for all time-trials. Figures represent percent of subjects reporting each focus.

\begin{tabular}{|c|c|c|c|c|}
\hline & Distance display & Treadmill noise & Lab conditions & Other \\
\hline BL & 89.29 & 17.86 & 0.00 & 3.57 \\
\hline KI & 92.86 & 3.57 & 0.00 & 7.14 \\
\hline UI & 89.29 & 3.57 & 0.00 & 3.57 \\
\hline
\end{tabular}

Table SDC3h. Outward monitoring category content at $2000 \mathrm{~m}$ for all time-trials. Figures represent percent of subjects reporting each focus.

\begin{tabular}{|c|c|c|c|c|}
\hline & Distance display & Treadmill noise & Lab conditions & Other \\
\hline BL & 96.43 & 17.86 & 0.00 & 10.71 \\
\hline KI & 85.71 & 3.57 & 0.00 & 7.14 \\
\hline UI & 96.43 & 3.57 & 0.00 & 3.57 \\
\hline
\end{tabular}

Table SDC3i. Outward monitoring category content at $\mathbf{3 0 0 0} \mathbf{~ m}$ for all time-trials. Figures represent percent of subjects reporting each focus.

\begin{tabular}{|c|c|c|c|c|}
\hline & Distance display & Treadmill noise & Lab conditions & Other \\
\hline BL & 96.43 & 14.29 & 0.00 & 0.00 \\
\hline KI & 92.86 & 7.14 & 0.00 & 14.29 \\
\hline UI & 96.43 & 0.00 & 0.00 & 14.29 \\
\hline
\end{tabular}

